\title{
Prospects of Genetics and Breeding for Low Phosphate Tolerance: an Integrated Approach from Soil to Cell
}

\section{Jonathan Odilón Ojeda-Rivera}

Texas Tech University

Gerardo Alejo-Jacuinde

Texas Tech University

Héctor-Rogelio Nájera-González

Texas Tech University

Damar López-Arredondo ( $\square$ Damar.Lopez-Arredondo@ttu.edu )

Texas Tech University https://orcid.org/0000-0001-7389-3143

\section{Research Article}

Keywords: Phosphorus uptake and use efficiency, targeted improvement, genome editing, synthetic biology, global food security, mutations, E. coli

Posted Date: November 1st, 2021

DOI: https://doi.org/10.21203/rs.3.rs-1022173/v1

License: (c) (i) This work is licensed under a Creative Commons Attribution 4.0 International License. Read Full License 


\section{Abstract}

Due to the importance of Phosphorus $(\mathrm{P})$ on plant development and reproduction, global $\mathrm{P}$ security has emerged as a key factor towards global food security. Together with multiple agrochemicals, P-based fertilizers have become the pillars that sustain our food production systems. Therefore, improving the genetics and biology of key crops such as maize, rice, wheat and soybean to develop varieties better adapted to thrive under environments that present low phosphate $(\mathrm{Pi})$ availability and that possess higher Pi-fertilizer use efficiency is imperative. In this review, we summarize the current understanding of $\mathrm{Pi}$ nutrition in plants, with particular focus on crops, and provide new perspectives on how to harness the ample repertoire of genetic mechanisms behind plant low-Pi adaptive responses that can be utilized to design smart low-Pi tolerant plants. We discuss on the potential of implementing more integrative, versatile and effective strategies by incorporating genome editing and synthetic biology approaches to reduce Pi-fertilizer input and enable global food security in a more sustainable way.

\section{Introduction}

Being an essential element for all living forms and the most restrictive nutrient that sets the pace and productivity of life, global Phosphorus $(P)$ status has a direct implication on global food security. Based on current growing population rates projected to reach about 10 billion by 2050 (UN Department of Economics and Social Affairs 2015), important goals should be achieved to feed the world. This implies achieving an increase in crop productivity of at least $70 \%$ without increasing agricultural land and by lowering environmental pollution at the same time (Ranganathan et al. 2018). Therefore, increasing the yield of key crops will be an important component of a sustainable food future. In this context, favoring low-P tolerance in crops through improvement of uptake and use efficiency will play an essential role towards designing high-yielding and better adapted plants to changing environmental conditions. This represents a great challenge not only because low $\mathrm{P}$ availability in agricultural soils compromises crop productivity but also because current food production systems are built on heavy application rates of Pfertilizers which pose an environmental risk. Furthermore, demand and supply of these fertilizers determine the $\mathrm{P}$ market economy which ultimately has a profound impact on the food production chain. Therefore, in this context, plant biology, biotechnology and genetic engineering are compelled to generate innovative solutions, some of them built on traditional breeding efforts, specifically focused on improving crop varieties to reduce P-fertilizer input and enable global food security in a more sustainable way.

In this review, we first discuss the role of $\mathrm{P}$ as an essential piece to achieve the above-mentioned goals. Then, we provide a brief description of the biological role of $\mathrm{P}$ in crop nutrition. We also summarize the current understanding of $\mathrm{P}$ nutrition in plants, with a particular focus on crops, and explain how this knowledge can be harnessed for targeted breeding of Pi uptake and use efficiency in crops. Our final purpose is to reveal the ample repertoire of genetic mechanisms behind low-P tolerance that can be utilized to design smart low-P tolerant plants. In this review, we will define $\mathrm{P}$ utilization efficiency as total crop dry matter production per unit of P applied, and uptake efficiency as the plant's ability to obtain P from the soil (Wang et al., 2010). 


\subsection{Phosphorus: an essential piece towards agricultural sustainability}

$\mathrm{P}$ is one of the most important macronutrients for the development of all known biological systems; it was very well described as "life's bottleneck" by the chemist and science writer Isaac Asimov a long time ago (Asimov 1974). P constitutes the backbone of essential biomolecules such as nucleic acids, membrane phospholipids and ATP, and is involved in crucial biological processes. Therefore, $\mathrm{P}$ nutrition is an essential piece within the food production chain and, thus, represents a challenge for agriculture.

The primary source of $P$ is the Earth's crust and its abundance is of $0.10-0.12 \%$ (on a weight basis), with most of $\mathrm{P}$ existing as inorganic phosphate ( $\mathrm{Pi}$ ) minerals (phosphate rock) and at lesser extend as phosphorus-containing organic compounds (Mackey and Paytan 2009). Under natural conditions, $P$ is made available by weathering of exposed P-bearing rocks and then it is inserted into the P cycles which set the pace and productivity of life. However, in agricultural systems, farmers tend to apply different sources of $\mathrm{P}$ to croplands to boosts yields. Applying manure, human excreta and minimally processed bones represented common $P$ fertilization practices in the past, however, with the advent of the Green Revolution, agriculture was industrialized. Improved crop varieties and a wide variety of Pi fertilizers including mono and di-ammonium $\mathrm{Pi}$, triple super $\mathrm{Pi}$, single super $\mathrm{Pi}$, and nitrogen-phosphorus-potassium (NPK) fertilizers are now widely marketed and applied at large scale to agricultural fields and have become the pillars that sustain our society's food systems (Pingali 2012; John and Babu 2021). Overall, $\mathrm{Pi}$ use as a nutrient $\left(\mathrm{P}_{2} \mathrm{O}_{5}\right)$ in agriculture in 2019 is calculated in almost 44 million tons (FAOSTAT 2021) and its demand is projected to increase up to 50 million tons in 2022 (FAO 2020). The world capacity for producing Pi in the same year was forecasted on about 46 million tons (FAO 2020), however, based on registered data at FAOSTAT only about 43 million tons were produced (FAOSTAT 2021). Although there might be certain variability on the reported data due to unforeseeable factors, overall, they suggest that we are approaching to a negative balance which makes Pi supply uncertain for the coming years. It is important to mention that the forecasted demand of Pi fertilizer is expected to increase mainly in Asia and moderately in Latin and Central America. However, no substantial increase is projected in Africa, where the Food and Agricultural Organization of the United Nations (FAO) estimated 282 million undernourished people in 2020, about $33 \%$ of the total globally (768 million) (FAO, IFAD, UNICEF 2021).

In contrast to $\mathrm{N}$-fertilizers which can be produced from a nearly infinite reservoir, our planet's atmosphere, via the Haber Bosch process, Pi rock deposits, the only source from which Pi-fertilizers are made, are nonrenewable. Therefore, a potential global $\mathrm{P}$ crisis has been discussed extensively during the last several years (for an extensive discussion see Cordell and White 2014). The study of different scenarios has projected the potential P peak, a global Pi depletion, to occur within the next 5 to 40 decades (Mohr and Evans, 2013; Van Vuuren et al., 2010; Walan, 2013; Cordell and White 2014). Numerous factors have been proposed to be associated with this potential crisis, for example: the geological distribution of the Pi rock reserves and resources, the economic power of farmers in different agricultural regions, a lack of clear policies for the global governance of the resource, and the socio-political issues associated with the $P$ 
market, just to mention a few. World resources of Pi rock have been calculated globally in more than 300 billion tons from which only about 71 billion tons are considered economically extractable reserves (Jasinski 2021). These reserves are not equally distributed; about $90 \%$ of the world's economically extractable reserves are found in only six countries: Morocco and Western Sahara, China, Algeria, Syria and Brazil. Mine production of Pi rock based on USGS system were estimated in 223 million tons in 2020 (Jasinski 2021).

Some argue that socio-economic/political and environmental factors, rather than the geo-localization of $P i$ rock availability, will be the real cause of the $P$ crisis which is directly influenced by the $P$ market, the production capacity, demand, and application rates. High-grade Pi reserves will be depleted sooner or later, thus, the remaining low-quality sediments which are more difficult to extract will require higher investments resulting in increased $\mathrm{Pi}$ fertilizer production costs. As compared to the $\mathrm{N}$ - and $\mathrm{K}$-fertilizers market, the P-fertilizer market has shown great fluctuation over the years suggesting its susceptibility to numerous factors. For example, phosphate DAP fertilizer price was about US\$300/ton in 2017 and increased to nearly US $\$ 400 / \mathrm{mt}$ in 2018 . After six consecutive quarterly declines with price ranging from US $\$ 254 / \mathrm{mt}$ to US $\$ 305 / \mathrm{mt}$, a surge of phosphate DAP fertilizer prices was registered again in the third quarter of 2020 (US\$358/mt) and has been rising to US\$643/ton in 2021 (The World Bank 2021). This fluctuation is largely attributed to the COVID-19 health pandemic. Abrupt changes were also registered in 2008 when our society faced a global crisis and when the price of Pi rock increased by $800 \%$ from US\$50/ton to US\$430/ton (Cordell and White 2014). Current agricultural practices rely on applying large amounts of fertilizers and agrochemicals (e.g. herbicides, insecticides), often used in excess, extensive areas of fertile land and vast amounts of fresh water which has led to deforestation, soil degradation and environmental pollution. Eutrophication caused by leaching and runoff of fertilized fields has raised concerns over the sustainability of $\mathrm{P}$ because excessive nutrient discharges feed toxic algal blooms which deplete oxygen levels and compromise water quality and aquatic life (Dodds et al. 2008; Bonsdorff 2021). Eutrophication affects more than 400 coastal water zones worldwide (called ocean "dead" zones) that have been ben calculated to cost about US\$2.2 billion annually in the United Estates only (Dodds et al. 2008; Diaz and Rosenberg 2008).

As there could be many more factors influencing the scarcity of Pi-rock reserves such as the development and/or improvement of $\mathrm{Pi}$ recycling and $\mathrm{Pi}$ mining technologies and the possible discovery of new Pisediments, a potential peak of $P$ is difficult to forecast. Nevertheless, because there are no substitutes for $\mathrm{Pi}$ in agriculture and the threat of $\mathrm{Pi}$ limitation is imminent, humanity will unavoidably face this crisis at some point. Global P security has a direct implication for global food security. Thus, science-driven disruptive and effective strategies and inclusive and equitable environmental-social-economic policies are urgently needed.

From mines to agricultural lands and then to water bodies, $\mathrm{P}$ has been described to predominantly flow in a one-way direction and get lost during many stages of the food production systems, including during $\mathrm{Pi}$ rock mining and processing, thus exceeding the "planetary boundaries" (Carpenter and Bennett 2011; Townsend and Porder, 2011), defined by Rockström et al. 2009 as "a safe operating space for humanity 
on Earth". Therefore, numerous strategies have been proposed from different perspectives (technological, socio-cultural, biological) to address this global challenge and solve the negative effects of current farming practices. These include the design of more effective and slow-release fertilizers, improvement of fertilization management practices, improvement of the Pi extraction process, design of Pi-recycling technologies, and the improvement of crop genetics and biology (Figure 1). The latter has received great attention over the last two decades and is the focal part of this review. Therefore, the challenge for modern agriculture is to produce more and better-quality food in a sustainable way for all the human population and to do so by significantly reducing dependency on Pi-based fertilizer use. Based on food demands of the continuously growing population, the global demand for crops is estimated to increase by $100-110 \%$ from 2005 to 2050 (Tilman et al. 2011), which indicates that reaching optimal crop yields will be crucial to fulfill these demands in the coming years. This goal is to be achieved through effective nutrient management by ensuring enough Pi availability for the plant without creating over-fertilization problems (Figure 1). However, a recent study tracked agricultural statistics for maize, rice, wheat and soybean, four key global cereals, suggests that based on historical yield increase rates (0.9-1.6\%), global production of these crops would be far below what is required in 2050 (Ray and Foley 2013). Therefore, there is an urgent need for transforming current food systems towards achieving sustainable Development Goals (SDG) targets 1 and 2, that consist in ensuring food security and ending hunger, respectively, and were set by FAO (FAO, IFAD, UNICEF 2021). This implies implementing effective and reoriented governance strategies which we believe should also include ways to boost the development and introduction into the market of improved crop varieties better adapted to thrive under low $P$ environments and/or to more efficiently use P-fertilizers which may be generated through modern techniques such as transgenesis and gene editing and by incorporating research and development at the systems level and synthetic biology approaches.

\subsection{Life's bottleneck: the essential role of Phosphorus in crops}

Together with $\mathrm{N}$ and $\mathrm{K}, \mathrm{P}$ in its inorganic form, orthophosphate $(\mathrm{Pi})$, is required in large amounts by any plant to successfully complete its normal life cycle. However, it is estimated that about 5.7 billion hectares of the available cropland worldwide present low $\mathrm{P}$ availability, which severely limits yield of key crops, including maize, rice and soybean, in tropical and subtropical soils (Batjes 1997). Thus, in an agricultural context where the goal is to produce the highest yield of grain or of any plant part that can be used directly or processed as food, $\mathrm{Pi}$ is provided mainly in Pi-based fertilizers. This practice is directly reflected in the average application rate of Pi-fertilizers ( $\mathrm{kg} / \mathrm{ha}$ of crop land) which has been registered in about $28.41 \mathrm{~kg} / \mathrm{ha}$ worldwide, with some peaks in Asia and South America reporting 44.35 and 46.15 $\mathrm{kg} / \mathrm{ha}$, respectively, and has remained relatively stable through the last 10 years (FAOSTAT 2021). However, the Pi-fertilizer application rate in Africa, where about one third of the global undernourished people exists, is extremely low as only about $5.87 \mathrm{~kg} / \mathrm{ha}$ are applied because farmers are not able to afford the high costs of Pi fertilizers (FAOSTAT 2021). 
Besides the biological and genetic makeup of the plant, there are numerous external factors influencing $\mathrm{Pi}$ availability and plant uptake rates, including: $\mathrm{Pi}$ chemical properties, soil properties ( $\mathrm{pH}$, cations), environmental conditions and agricultural practices. Low Pi availability severely affects crop yield and reduces agricultural production by up to $40 \%$ (Malhotra et al. 2018). For example, soil Pi availability is limited because $\mathrm{Pi}$ is practically immobile in the soil, thus, being very susceptible to adsorption and precipitation making Pi unavailable for plant uptake (Hinsinger 2001; Yu et al., 2021). Furthermore, cations such as $\mathrm{Ca}^{+2}, \mathrm{Al}^{+3}, \mathrm{Mg}^{+2}$ strongly interact with $\mathrm{Pi}$, limiting even more its availability. Another factor that contributes to limiting Pi levels is soil erosion by water which is predicted to deplete croplands worldwide at an alarming rate of 4-19 kg/ha per year which might represent up to $50 \%$ of soil-Pi losses in the coming years (Alewell et al. 2020). Other factors like climate change, including increases in mean annual temperatures and the increase of mean annual precipitation can decrease soil Pi availability by decreasing mineral Pi availability and organic Pi levels in the soil (Hou et al. 2018). A heatmap that summarizes the main factors and the estimated size of their influence on Pi-limitation effects on aboveground productivity is presented in Figure 2a (illustrated using the ComplexHeatmaps R package by Gu et al. 2016; based on the data analysis provided in Hou et al. 2020 and Yu et al. 2021).

Plants take up Pi from the soil solution via Pi transporters and then concentrate it up to $100 \mathrm{mg} \mathrm{L}^{-1}$ in the xylem sap and around 4,000 mg kg${ }^{-1}$ in the seed (Tiessen 2008; Versaw and Garcia 2017), indicating that Pi needs to be supplied at adequate levels to maintain crop productivity. At a first level, physiological and metabolic mechanisms allow the plant to cope with both excessive and deficient Pi levels so it can thrive under either condition. When Pi levels are too high, the plant prevents Pi toxicity by increasing Pi efflux and storage in the vacuoles and reducing the activity of Pi transporters (Schachtman et al. 1998). When $\mathrm{Pi}$ is low, the plant activates a series of mechanisms including the activation or enhancement of high affinity Pi transporters, the remobilization and recycling of Pi from non-essential molecules and the enhancement of its interaction with the rhizosphere to take advantage of dissolved Pi. All these mechanisms constitute the general response of the plant to low Pi availability and will be explained in more detail in the following sections.

Even though current P-fertilization rates are high, Pi-fertilization in general is very inefficient as it has been estimated that this practice only increases plant production in croplands by roughly $15-18 \%$ (Hou et al. 2020; Yu et al. 2021). Pi-fertilization practices are inefficient because of the previously mentioned factors that diminish $\mathrm{Pi}$ availability in the soil; a heatmap summarizing the effects of these factors and the extent of their influence on the effect of Pi-fertilizer on above-ground plant production is presented in Figure $2 \mathrm{~b}$. Moreover, the most important cereal crops including maize, rice, wheat, barley are largely inefficient in $\mathrm{Pi}$ fertilizer use efficiency which is in average less than 10\% (Figure 2c; Yu et al. 2021). After fertilization, the remaining Pi gets fixed into soil particles and becomes part of the so-called pool of residual $P$ (difference between $P$ inputs and $P$ outputs) or legacy $P$ (Pavinato et al. 2020). Importantly, large fractions of legacy $\mathrm{P}$ can be made naturally available i.e. by changes in soil properties either caused by the climate conditions, the plant and/or its associated microbiome, and further removed and taken up in subsequent years (Khan et al. 2007; Sharpley et al. 2013; Pavinato et al. 2020). This has been demonstrated 
previously by Gatiboni et al. 2021 by crop rotation experiments. Therefore, legacy P might play an essential role in increasing or at least maintaining crop productivity and decreasing P-fertilizers use and environmental pollution in the near future (Sattari et al. 2012; Alewell et al. 2020), with the additional potential benefit of minimizing cropland expansion. Interestingly, a recent study suggests that increasing P-fertilization by $7 \%$ in the P-depleted soils in sub-Sahara Africa would boosts crop production and contribute to meet the global food demand by 2050, and thereby, decrease cropland expansion (Mogollón et al. 2021). We believe that if this strategy is devised as one of the most feasible and realistic strategies to face the global food $\mathrm{P}$ crisis, it should be undoubtedly accompanied by improved crops equipped with an arsenal of traits to succeed under such adverse environmental growth conditions.

\section{Plant Adaptive Mechanisms Associated With Low Phosphate Conditions}

Understanding how plants adapt to Pi starvation is crucial because Pi availability is often limiting in natural and agricultural ecosystems. Several crops and model plants have served as models to study plant responses to Pi deprivation at different levels (i.e. metabolic, physiological and molecular) which has broadened our understanding of metabolic and organ plasticity in response to Pi starvation, $\mathrm{Pi}$ sensing mechanisms and how key molecular regulators work to trigger adaptive molecular responses that enable plant development when $\mathrm{Pi}$ is limiting. Plant molecular responses to $\mathrm{Pi}$ availability can be broadly categorized into two types of responses: local and systemic responses, as has been proposed for Arabidopsis (Péret et al. 2011). Local responses depend on the external concentrations of Pi that the root is in contact with and modulate modifications of root architecture and the exudation of organic acids in response to low external Pi levels. Systemic responses comprehend the activation of physiologic, metabolic and molecular adjustments at the whole plant level when internal Pi homeostasis is compromised. This dissection of molecular responses originated from a transcriptomic characterization of Arabidopsis split-root systems that were exposed to contrasting Pi-concentrations and were found to respond locally and systemically to Pi deprivation (Thibaud et al. 2010). Of special interest is to understand that these responses are not completely independent and that there is evidence of crosstalk between local and systemic signaling in Pi-deprived plants (Mora-Macías et al. 2017). However, this dissection provides a framework that we will use to explain and summarize findings on both the plant adaptive mechanisms and the molecular components that sense and control responses to both internal and external Pi levels, and how these regulatory modules can be used to improve low phosphorus tolerance.

\subsection{Systemic responses}

\subsubsection{Phosphate uptake and translocation}

Because $\mathrm{Pi}$ is required at a higher concentration inside the plant cell than it is in the soil solution, it must be actively taken up against a concentration gradient by Pi transporter proteins present in the plasma 
membrane of epidermal root cells. Pi is then distributed symplastically across the root to reach the xylem and the aerial parts of the plant (López-Arredondo et al. 2014; Malhotra et al. 2018). Plants possess two types of Pi transporter proteins that enable Pi acquisition: low-affinity Pi transporters with affinity constant $\left(K_{m}\right)$ values in the 50-300 $\mu \mathrm{M}$ range, and high-affinity Pi transporters with a $K_{m}$ in the 3-10 $\mu \mathrm{M}$ range (Raghothama 1999; Hasan et al. 2016). High-affinity Pi transporters in plants are encoded by PHOSPHATE TRANSPORTER (PHT) genes which are phylogenetically classified into five families (PHT15; (Wang et al. 2017)) from which members of the PHT1 family of high affinity Pi transporters are known to be mainly involved in root-mediated Pi uptake from soil. PHT1 genes are systemically induced in Arabidopsis under Pi-limiting conditions (Raghothama and Karthikeyan 2005; Thibaud et al. 2010). PHT1 transporters have been characterized in Arabidopsis and several crops such as maize, rice, wheat, soybean, tomato, and barley (for review see Wang et al. 2017). In the case of Arabidopsis, AtPHT1;1 and AtPHT1;4 account for up to $75 \%$ of total plant Pi uptake (Shin et al. 2004). In rice, OsPHT1;4 is the main transporter involved in root-mediated $\mathrm{Pi}$ uptake and its overexpression leads to Pi over-accumulation in roots (Ye et al. 2015). Moreover, maize ZmPHT1 genes are induced by Pi starvation and mediate the symbiotic association with Arbuscular Mycorrhizal Fungi (AMF) which provides Pi uptake for the plant in exchange for carbohydrates for the fungi in Pi-deficient soils (Willmann et al. 2013; Liu et al. 2018a). Phosphate transporters upregulated by AMF in rice (OsPT11/13) and soybean (GmPT7/10/11) support a role for plant Pi uptake at this symbiotic interface (Tamura et al. 2012; Yang et al. 2012).

The root cap, which stands at the forefront of soil exploration, has been described to enable up to $20 \%$ of the total plant Pi uptake. Interestingly, AtPHT1;4 is predominantly expressed in this region of the root, and root-cap-mediated Pi uptake was reported to occur in rice and lotus (Kanno et al. 2016) which indicates that this mechanism for Pi uptake might be present in many plant species. Furthermore, proteins that belong to the PHT1-5 families of Pi transporters play additional roles involved in maintaining Pi homeostasis, either by facilitating Pi uptake or by enabling remobilization of internal Pi among different tissues or organelles. This is particularly important because several studies have shown that most of the $\mathrm{P}$ in the cell is stored in the vacuole, while only $1-5 \%$ is present in the cytoplasm (Raghothama and Karthikeyan 2005; Wang et al. 2017; Versaw and Garcia 2017). In Arabidopsis, once Pi is taken up by the root cells, root-to-shoot translocation of $\mathrm{Pi}$ is enabled by AtPHOSPHATE1 (AtPH01), a protein involved in xylem Pi loading (Poirier et al. 1991; Hamburger et al. 2002). Orthologs for AtPHO1 have been identified and characterized to have similar functions in soybean, rice and maize (Secco et al. 2010; Salazar-Vidal et al. 2016; Wang et al. 2019c).

\subsubsection{Phosphate scavenging and remobilization}

Besides the induction of high affinity $\mathrm{Pi}$ transport and translocation in response to low $\mathrm{Pi}$, systemic responses in plants also comprehend the activation of Pi remobilization, scavenging and recycling mechanisms. Plants recycle Pi from the hydrolysis of phospholipids which leads to an increase in internal Pi availability (Plaxton and Tran 2011); non-phosphorus lipids like galactolipids and sulfolipids replace phospholipids to maintain the functionality and structure of the plasma membrane. Enzymes in Arabidopsis that are involved in this process include PHOSPHOLIPASE D ZETA 2 (AtPLDZ2) and 
MONOGALACTOSYL DIACYL GLICEROLASE SYNTHASE 1-2 (AtMGDG1-2) and DIACYL GLICEROLASE SYNTHASE 1-2 (AtDGDG1-2) and SULFOQUINOVOSYL DIACYL GLYCEROL SYNTHASE 1 (AtSQD1) (Essigmann et al. 1998; Awai et al. 2001; Kelly et al. 2003; Cruz-Ramírez et al. 2006; Plaxton and Tran 2011). As indicated by the names of these enzymes, they play roles in phospholipid breakdown and the further synthesis of substitute monogalactosyl-, digalactosyl- and sulfoquinovosyldyacylglycerol- lipids. Moreover, a novel non-phosphorus lipid, glucoronosyldiacylglycerol, has been reported to accumulate in Pi-deprived Arabidopsis and rice plants (Okazaki et al. 2013). Phospholipid hydrolysis and Pi recycling from nucleic acids, through the induction of nuclease-coding genes, contribute to buffering the cytosolic Pi pools when systemic levels of Pi are limiting (Plaxton and Tran 2011; Jeong et al. 2017). Maintaining adequate cytosolic Pi levels is key as low levels of cytosolic Pi have a negative effect on photosynthesis which eventually leads to the inhibition of plant growth and development (Ajmera et al. 2019). Fine tuning of Pi recycling and remobilization has been proposed as a key breeding target for producing Pi-use efficient genotypes (Heuer et al. 2017) because it could enable plants to release and mobilize Pi from phospholipids without compromising photosynthesis. An example of this optimization is found in species naturally occurring in soils with extreme Pi scarcity like the Proteaceae. Plants belonging to this family predominantly use galactolipids and sulfolipids instead of phospholipids in mature photosynthetic leaves allowing them to maintain high photosynthetic Pi use efficiency and thrive on the sands of southwestern Australia (Lambers et al. 2011, 2012).

Pi scavenging in plants is promoted through the upregulation of genes that code for acid phosphatases (AP) and purple acid phosphatases (PAPs), which can be secreted and hydrolyze Pi from organic phosphate esters present in a wide variety of organic compounds including nucleic acids, ATP, 3phosphoglycerate and various hexose-Pi compounds (Hurley et al. 2010). A large group of these proteins is induced as part of the systemic response to Pi starvation and help the plant in Pi uptake and reutilization (Hurley et al. 2010; Thibaud et al. 2010; Pandey 2020). PAPs, called that way because of their color in solution and their optimal working $\mathrm{pH}$, are the largest class of AP. Twenty-nine PAPs have been found in Arabidopsis, of which AtPAP26 is the predominantly secreted and intracellular phosphatase (Li et al. 2002; Hurley et al. 2010). Root secreted PAPs release Pi from organic P-compounds which can constitute up to $80 \%$ of total P content in soil (Raghothama 1999). AtPAP10 and AtPAP12 are not excreted, but associated with the root surface, increasing the availability of Pi where it is useful for the plant (Tran et al. 2010; Wang et al. 2011). Vacuolar or other intercellular PAPs are expressed in stagespecific and tissue-specific fashion to mobilize Pi from storage organelles or from senescent leaves (Gao et al. 2017). Thirty-three putative PAPs have been identified in maize (González-Muñoz et al. 2015), thrirty-five in soybean (Li et al. 2012), and twenty-six in rice (Oryza sativa, (Zhang et al. 2011)). Enhanced levels of PAPs remains an interesting perspective to boost Pi uptake in crops.

\subsection{Local monitoring of external phosphate availability}

Local responses to low Pi levels comprehend the modifications of root development and the subsequent root morphology and architecture remodeling in response to the concentrations of external Pi that the root, or a portion/section of the root, is in contact with. Earliest evidence of this type of response was 
reported in common bean plants in which root architecture is modified in response to Pi supply (Lynch and Brown 2001). Subsequent reports in the model plant Arabidopsis corroborated that low Pi concentrations induce morphological changes in the root (López-Bucio et al. 2002). These responses are regulated in local fashion, at least at the transcriptional level, independently of the systemic $\mathrm{Pi}$ homeostasis status of the plant (Thibaud et al. 2010; Péret et al. 2011). Root architecture plasticity is crucial for plant adaptation to Pi deficiency because the Pi-uptake capacity is greatly contributed by their ability to explore the soil.

As previously explained, $\mathrm{Pi}$ is an immobile nutrient that is easily fixated in the topsoil, concomitantly, root architecture modifications are oriented to the development of a shallow root architecture in order to more efficiently explore the top layers of the soil when Pi levels are limiting; this adaptation is known as topsoil Pi foraging (Lynch and Brown 2001). Modifications of root architecture and morphology have been extensively reviewed and include an increase in the density and length of root hairs (Bates and Lynch 1996), an increase in the emergence of lateral roots with a shallower root angle (Lynch and Brown 2001; López-Bucio et al. 2002; Rellán-Álvarez et al. 2015), the formation of adventitious roots (Ochoa et al. 2006) and the inhibition of primary root growth (see Gutierrez-Alanís et al. 2018 for review). Additionally, there are some less common root morphology adaptations that are triggered in response to limited $\mathrm{Pi}$ availability like the formation of dense interspaced clusters of lateral roots called 'cluster roots' which is associated to environments with extreme Pi scarcity (Lambers et al. 2012). Plants that induce the formation of cluster roots secrete organic acids profusely through these structures to perform anion displacement and release fixated Pi from the soil (Lambers et al. 2012). Being a developmental response, root system architecture modification is determined by the dynamics of different phytohormones. Low external Pi increases the root sensitivity to auxin which has been described as a key component regulating lateral root growth (López-Bucio et al. 2002). Whereas the growth of the primary root is inhibited due to meristem exhaustion (Sánchez-Calderón et al. 2005) and an increase in lateral root formation due to increased mitotic activity are observed during Pi deprivation in Arabidopsis (Ajmera et al. 2019). The formation of new lateral roots is regulated by the auxin receptor TIR1 and the transcription factors ARF7/19 (Auxin Response Factor 7 and 19) in Arabidopsis (Pérez-Torres et al. 2008).

\section{Genetic Regulation Of Low Phosphate Adaptations}

\subsection{Regulons controlling phosphate homeostasis}

Systemic transcriptional responses to Pi deprivation are largely controlled by the MYB transcription factor PHOSPHATE STARVATION RESPONSE 1 (PHR1) which was first discovered in Arabidopsis (Rubio et al. 2001). AtPHR1 regulates the expression of low-Pi responsive genes by binding to the palindromic sequence GNATATNC which is known as PHR1-Binding Site (P1BS) and is present in the promoter sequences of its target genes (Bustos et al. 2010). AtPHR1 has orthologs that play a similar function in several crop species including maize ZmPHR1 (Calderón-Vázquez et al. 2011), rice OsPHR2 (Zhou et al. 2008), common bean PvPHR1 (Valdés-López et al. 2008) and wheat TaPHR1 (Wang et al. 2013). 
When Pi levels are limiting, PHR1 transcription factors upregulate the expression of high affinity PHT1 transporters (Nussaume et al. 2011). Pi transport is followed by root-to-shoot translocation of Pi that is enabled by AtPHOSPHATE1 (AtPHO1), a protein involved in xylem Pi loading (Poirier et al. 1991; Hamburger et al. 2002). Orthologs for PHO1 have been identified and characterized to have similar functions in soybean (Glycine max), rice (Oryza sativa) and maize (Zea mays) (Secco et al. 2010; Salazar-Vidal et al. 2016; Wang et al. 2019c). Characterization of Ospho1;2 rice mutant plants revealed defects in Pi translocation from root to shoot, however, OsPH01;2 expression is not responsive to $\mathrm{Pi}$ deprivation which suggests post-transcriptional activation of OsPH01;2 mechanisms under Pi deficiency (Secco et al. 2010). Interestingly, it was discovered that a cis-Natural Antisense Transcript (cis-NAT) cis$N A T_{P H 01 ; 2}$ present in the OsPHO1;2 locus is induced in response to Pi deficiency and stimulates PH01;2 accumulation by enhancing its translation independently of PHO1;2 mRNA levels (Jabnoune et al. 2013). The cis-NAT, cis-NAT ${ }_{\text {PHO1;2a, }}$ was also found out to be present in one of the four AtPHO1 orthologs in maize, $Z m P H O 1 ; 2 a$, and its expression is induced by low Pi availability (Salazar-Vidal et al. 2016). This suggest that its upregulation might play a similar role as in rice by enhancing translation of the $\mathrm{ZmPHO1;2a}$ paralog $\mathrm{ZmPHO1;2b}$ gene. These reports highlight cis-NAT regulation of ZmPHO1 translation as an interesting perspective for studies, engineering and/or breeding of Pi homeostasis and $\mathrm{Pi}$ translocation in crops. A schematic summary of cis-NAT mediated control of Pi translocation in plants is presented in Figure 3a.

AtPHOSPHATE2 (AtPHO2), a ubiquitin E2-ligase, is a protein with a key role in Pi homeostasis in Arabidopsis because it regulates the ubiquitin-mediated degradation of Pi transporter proteins PHT1-4 and the phosphate translocator AtPHO1, thus preventing Pi shoot toxicity (Liu et al. 2012; Huang et al. 2013). To promote Pi translocation, AtPHO2 transcripts are negatively regulated under low Pi conditions by the microRNA Atmir399 (Bari et al. 2006). Under Pi starvation conditions, AtPHR1 upregulates the expression of Atmir399 genes most likely through binding to P1BS sequences present in the promoter of Atmir399 genes (Bari et al. 2006; Hsieh et al. 2009) as revealed by Chip-Seq analysis (Castrillo et al. 2017). AtPHR1 induces Atmir399 expression in response to low Pi availability, therefore, triggering Atmir399-dependent downregulation of AtPHO2 which defines a Pi-dependent regulon in Arabidopsis (Bari et al. 2006). Atmir399-output is also modulated by AtIPS1, a long noncoding RNA (IncRNA) that contains a motif with sequence complementarity to Atmir399. Under Pi deficiency, AtIPS1 expression is induced by AtPHR1 and, due to its complementarity with Atmir399, AtIPS1 sequesters Atmir399 to prevent the cleavage of PHO2 transcript (Franco-Zorrilla et al. 2007). The discovery of this regulon revealed target mimicry as a biological mechanism to inhibit miRNA activity (Franco-Zorrilla et al. 2007). There is conservation of the PHR1-mir399-IPS1 regulon in various plant species, including crops such as maize, rice, common bean, and soybean (Valdés-López et al. 2008; Hu et al. 2011; Xu et al. 2013; Du et al. 2018). In the case of maize, the Pi-deficiency-induced long non-coding RNA 1 (PILNCR1) is induced by Pi deficiency and inhibits Zmmir399-guided cleavage of ZmPHO2 transcripts (Du et al. 2018). Moreover, PILNCR1 expression was shown to be higher in P-inefficient maize lines and PILNCR1-overexpressing lines over-accumulate P in shoots (Du et al. 2018). In bean, both Pv4 (PVIPS1) and Pvmir399 are induced in response to Pi deficiency and $\mathrm{PVPHO} 2$ expression is downregulated in Pi-deprived bean plants.

Page $11 / 52$ 
Moreover, RNA-interference (RNAi) lines silenced in PVDICERLIKE1 (PVDCL 1), a DICER-like enzyme implicated in miRNA biogenesis in Phaseolus vulgaris, accumulate more PvPHO2 transcripts under low $\mathrm{Pi}$ conditions corroborating involvement of miRNA signaling in the response to Pi deficiency in Phaseolus (Valdés-López et al. 2008). In rice, OsIPS1 and OsIPS2 are induced by OsPHR2 and OsPHO2 is downregulated by Osmir399 and Osmir399 overexpression which results in Pi over-accumulation in shoots (Hu et al. 2011). A schematic summary of miRNA-mediated control of PHO2 transcript levels in plants is presented in Figure $3 \mathrm{~b}$.

Another ubiquitin-ligase that controls Pi homeostasis in plants is NITROGEN LIMITATION ADAPTATION 1 (NLA) which activates the degradation of PHT1 Pi transporter proteins via ubiquitin-mediated endocytosis in Arabidopsis (Lin et al. 2013) and rice (Yue et al. 2017). Like AtPHO2 which is downregulated by the low-Pi inducible Atmir399, AtNLA1 is also negatively regulated by the Atmir827 microRNA that is induced upon Pi-starvation (Kant et al. 2011). Even though both NLA1 and PHO2 regulate turnover of Pi transporter proteins, they have been reported to act independently as they do not interact with each other (Lin et al. 2013; Yue et al. 2017); both NLA1 and PHO2 prevent Pi toxicity when Pi levels are high. A schematic summary of ubiquitin-mediated turnover of Pi-transporter proteins in plants is presented in Figure 3c.

\subsection{Regulation mechanisms by inositol polyphosphate sensing}

Because PHR1 transcription factors activate the transcriptional activity of multiple genes that enable plant adaptation to Pi-scarcity, an interesting question in the plant molecular biology of Pi sensing is the regulation of PHR1 transcription factors. Since AtPHR1 was discovered, it was reported that the expression of AtPHR1 remains largely unchanged in response to Pi deprivation (Rubio et al. 2001), indicating that its activity is most likely regulated at the post-transcriptional level in response to $\mathrm{Pi}$ limitation, subsequent evidence would prove this is the case.

Regulation of PHR1 transcription factors is known to be under control of SPX (SIG1-Pho81-XPR1) regulatory proteins in Arabidopsis and rice (Puga et al. 2014; Wang et al. 2014). Earliest evidence demonstrated that SPX1 binds to AtPHR1 in plants grown under optimal Pi conditions inhibiting its activity as transcription factor (Puga et al. 2014). Interestingly, AtPHR1 induces AtSPX1 expression when $\mathrm{Pi}$ levels are limiting, forming a negative regulatory loop that was proposed to enable the plant to rapidly turn off PHR1 activity upon Pi refeeding or a sudden increase in cellular Pi levels (Figure 4a). The PHR1SPX1 regulon was simultaneously reported in rice in which OsSPX1 and OsSPX2 were shown to interact with OsPHR2 and inhibit its binding to P1BS sites in a Pi-supply dependent fashion (Wang et al. 2014). Reports on the AtPHR1-SPX1 and OsPHR2-SPX1-2 regulons provided the first example of a Pi-sensing mechanism in plants. Further investigation of proteins with SPX-domain in rice and Arabidopsis demonstrated that SPX proteins are cellular sensors of inositol-polyphosphate (IP) levels (Figure 4a) that selectively interact with target transcription factors in the presence of IP molecules (Wild et al. 2016). These authors demonstrated that OsSPX4-OsPHR2 interact at $\mathrm{IP}_{7}$ concentrations as low as $20 \mathrm{uM}$ 
whereas previous reports indicated that $15 \mathrm{mM}$ Pi was required to promote the binding of OsSPX repressors to OsPHR2 (Wang et al. 2014). Furthermore, calorimetry titration experiments using an OsSPX4-OsPHR2 1:1 protein solution revealed that Pi did not induced binding of the complex, rather, $\mathrm{IP}_{6}$ and $\mathrm{IP}_{7}$ bound the complex with a Kd of 50 and $7 \mathrm{uM}$, respectively (Wild et al. 2016). Altogether, these data suggest that internal Pi homeostasis in plants is controlled by IP molecules, rather than Pi itself, and that IP levels control the SPX-dependent inhibition of PHR-like transcription factors in plants. However, the finding that phosphite, a reduced form of $P$ that cannot be metabolized by plants, also promotes the binding of SPX proteins to PHR1 suggests that Pi might have a biological activity to act as a signaling molecule in the Pi sensing mechanism.

It is likely that, besides their role in the regulation of transcription factor activity, SPX-regulatory proteins play additional roles in the regulation of Pi homeostasis. In addition to the four and six standalone SPX domain proteins we can find in the Arabidopsis and rice genomes, respectively, there are several SPXdomain containing proteins coded in both genomes (16 in Arabidopsis and 9 in rice) (Zhou et al. 2015). Examples of these proteins include the previously mentioned Pi translocator PHO1 and NLA1. In the case of AtPHO1 the function of the SPX-domain is unknown, however, data indicates that it is not essential for $\mathrm{Pi}$ export which offers the rationalization that SPX is likely involved in regulating AtPHO1 Pi-translocation activity (Wege et al. 2016). AtNLA1 and OsNLA1 interact with Pi transporters via their SPX domain (Lin et al. 2013; Yue et al. 2017), which highlights the function of SPX domains as target recognition domains which are activated by IP (Figure 3c). Because SPX-domain containing proteins have been identified and functionally validated to be present in most crops in addition to rice (see Liu et al. 2018b for review), their study and manipulation remains an interesting perspective for breeding approaches to generate low $\mathrm{Pi}$ tolerant crop varieties.

More recent studies have focused on the nature of the IP molecule that regulates Pi homeostasis in Arabidopsis through the SPX-PHR regulon. Two independent research groups reported simultaneously on the role for two enzymes, AtVIH1 and AtVIH2, that have dual pyrophosphate-kinase/phosphatase activity and that regulate $\mathrm{IP}_{8}$ levels in Arabidopsis (Zhu et al. 2019; Dong et al. 2019). Atvih1vih2 double mutants showed Pi starvation response genes constitutively activated even under high $\mathrm{Pi}$ availability conditions, and no detectable levels of $\mathrm{IP}_{8}$. Moreover, $\mathrm{IP}_{8}$ was shown to correlate with the intracellular concentration of $\mathrm{Pi}$ indicating the role of $\mathrm{IP}_{8}$ as a Pi-homeostasis signaling molecule in Arabidopsis (Zhu et al. 2019; Dong et al. 2019). Further biochemical and genetic studies revealed that AtSPX1 binds to the coiled-coil (CC) domain of AtPHR1 through the exposed residues (K325, H328, R335) and that this interaction disrupts AtPHR1 oligomerization which is essential for its activity as a master regulator of Pi starvation responses (Ried et al. 2021). Furthermore, nuclear magnetic resonance (NMR) spectroscopy data suggest that SPX proteins can bind IP ${ }_{8}$, however, NMR data also suggest that AtPHR1 does not bind IP 8 (Ried et al. 2021). These data indicate that $I_{8}$-SPX binding most likely stabilizes SPX which then stimulates its interaction with its target transcription factors and, in the case of the AtSPX1-AtPHR1 complex, impedes AtPHR1 oligomerization and its activity as a transcription factor. This mechanism of SPX-activation agrees with previous crystallization studies of SPX-IP ${ }_{6}$ complexes which suggested that binding of $\mathrm{IP}_{6}$ 
stabilizes the SPX a-helical hairpin and might enable SPX-domain containing proteins to interact with Pihomeostasis regulators in eukaryotes (Wild et al. 2016).

Interestingly, Arabidopsis Atipk 1 and Atitpk1 mutants which are defective in the synthesis of $\mathrm{IP}_{5}$ and $\mathrm{IP}_{6}$ are also altered in Pi homeostasis (Kuo et al. 2018), suggesting that specific species of IP might play a specific role in the regulation of plant $\mathrm{Pi}$ homeostasis and that it is not solely controlled by $\mathrm{IP}_{8}$. In support of this notion, a recent report of novel alleles of Atvih1 and Atvih2 double mutants showed that $\mathrm{IP}_{8}$ levels are downregulated in these mutants, however, the expression of AtPHR1 targets remains responsive to Pi deprivation (Land et al. 2021). Because $\mathrm{IP}_{6}, \mathrm{IP}_{7}$ and $\mathrm{IP}_{8}$ can bind the SPX domain (Wild et al. 2016), further in planta studies on the specific roles of IPs individual species are required. However, these studies might be challenging as they might require the development of strategies that inhibit specific $\mathbb{P}_{6 / 7 / 8}$ synthesis without compromising the abundance of each other. Functional analysis of orthologs for AtVIH1-2 in other plant species will allow to determine whether $\mathrm{IP}_{8}$ signaling is indeed a conserved signaling molecule regulating SPX activity in plants or whether different IP species act as signaling molecules in different species. A schematic summary of IP synthesis in Arabidopsis is presented in Figure 4b).

IPs do not mediate the formation of the At-SPX1-AtPHR1 complex in the same manner as it happens with the auxin receptor TRANSPORT INHIBITING RESPONSE 1 (TIR1) and AUX/IAA protein. In this case, binding is mediated by IAA (indole-3-acetic acid: auxin) acting as a "molecular glue" that enables the ubiquitin ligase AtTIR1 to bind and ubiquitylate the AtAUX/IAA repressors of the auxin response and target them for degradation (Tan et al. 2007). It is also interesting to note that $\mathrm{IP}_{6}$ acts a cofactor of the previously mentioned AtTIR1-AtAux/IAA auxin sensor. Likewise, IP ${ }_{5}$ is essential for the formation of the jasmonic acid sensing complex assembled by CORISMATE INSENTIVE 1 (AtCOI1) and JASMONATE ZIMDOMAIN PROTEINS (AtJAZ) (Sheard et al. 2010). The involvement of IPs in plant hormone sensing pathways suggests that synthesis of this signaling molecules might connect and adapt hormone responses according to Pi status. However, further studies on IP synthesis and its relationship with hormone responses are required to explore this possibility.

\subsection{Epigenetic regulation mechanisms activated under plant phosphate starvation}

There has been extensive characterization of plant transcriptional responses to Pi deprivation, however, there are only a few recent examples of epigenetic responses that are triggered in response to Pi stress. Epigenetic regulation is important because changes in chromatin structure and DNA modifications influence plant adaptation to stress conditions (Grimanelli and Roudier 2013; Zhang et al. 2018a; Séré and Martin 2019). Whole genome cytosine DNA methylation (mC) dynamics have been shown to respond to $\mathrm{Pi}$ availability in multiple plant species including tomato, soybean, rice and Arabidopsis (Secco et al. 2015; Yong-Villalobos et al. 2015; Chu et al. 2020; Tian et al. 2021). A. thaliana mutants defective in mC present disrupted responses to low $\mathrm{Pi}$ availability including increased lateral root density, less phosphatase activity and reduced total P content (Yong-Villalobos et al. 2015). Moreover, global mC 
changes in Arabidopsis and soybean correlate with the regulation of expression of a set of low-Pi responsive genes, however, in the case of tomato and rice, Pi-deprivation induced changes in global $\mathrm{mC}$ patterns do not correlate with global changes in gene expression (Tian et al. 2021). Therefore, a clear role for global $\mathrm{mC}$ dynamics on the regulation of genome-wide gene expression during plant Pi starvation has not been established, rather it seems that there is methylation of a specific set of Pi-starvation responsive genes and that this might happen in tissue-specific fashion (Secco et al. 2015; Yong-Villalobos et al. 2015). Interestingly, data indicates that transposable elements are enriched in $\mathrm{mC}$ in response to $\mathrm{Pi}$ limitation, which has been suggested to protect genome stability by preventing the expression of detrimental transposable elements during chromatin changes that might take place during Pi starvation (Secco et al. 2015; Yong-Villalobos et al. 2015; Chu et al. 2020; Tian et al. 2021). Thus, methylationdirected transposable element silencing seems to be a conserved mechanism conserved among multiple plant species including crops, nonetheless, more studies are required on the subject to further understand additional roles of $\mathrm{mC}$ in plant adaptation to low Pi conditions. Another epigenetic regulatory mechanism of gene expression is the modification of chromatin accessibility (Kornberg and Lorch 2003; Mellor 2005).

We recently showed that Pi-deprived root cells of Arabidopsis undergo genome-wide changes of chromatin accessibility and that AtPHR1 plays a key role in determining this remodeling of chromatin accessibility during Pi starvation (Barragán-Rosillo et al. 2021), providing yet another role for PHR1 in the Pi starvation of plants. Furthermore, it was demonstrated that up to $40 \%$ of rice genes undergo chromatin state changes in response to low Pi availability and that genes that are differentially expressed in response to $\mathrm{Pi}$ limitation are overrepresented in this set of genes with low-Pi activated chromatin dynamics (Foroozani et al. 2020). Another chromatin modification, histone deacetylation, was recently shown to repress the transcriptional activation of genes related to the modification of root architecture in response to low Pi in Arabidopsis (Xu et al. 2020). Altogether, recent evidence highlights the importance of epigenetic regulation on plant adaptation to low $\mathrm{Pi}$ availability and its value as the foundation for the development of innovative genome manipulation tools that might enable breeders to produce low-Pi tolerant crops (Figure 5).

\subsection{Control of root changes}

Changes of root architecture in response to low $\mathrm{Pi}$ availability are variable among species and there is not detailed mechanistic description of local Pi sensing at the root. However, some of the molecular components that trigger the regulation of root growth in response to external $\mathrm{Pi}$ concentrations have been characterized. The regulation of primary root growth in Arabidopsis is the most thoroughly characterized developmental program at the molecular level that is regulated by external Pi availability and has been reviewed elsewhere (Abel 2017; Gutiérrez-Alanís et al. 2018). These studies highlighted the role of the transcription factor SENSITIVE TO PROTON RHIZOTOXICITY 1 (AtSTOP1) and its target ALUMINUM ACTIVATED MALATE RESPONSE 1 (AtALMT1) in adjusting root meristematic activity and root elongation in response to external $\mathrm{Pi}$ availability via a malate-exudation-dependent ROS signaling mechanism (Balzergue et al. 2017; Mora-Macías et al. 2017; Godon et al. 2019). This mechanism has been recently 
shown to be facilitated by AtMEDIATOR16, which also acts a transcriptional co-activator of several low-Pi responsive genes including AtALMT1 (Raya-González et al. 2021). AtSTOP1 and AtALMT1 were first described to contribute to Arabidopsis tolerance to acidic $\mathrm{pH}$ and increased Al availability that prevails in acidic soils by activating and mediating, respectively, organic acid exudation (Hoekenga et al. 2006; luchi et al. 2007). Interestingly, in addition to high levels of Al and Fe cations, low Pi availability is also a common constrain to plant development in acidic soils due to a high Pi fixation in acidic soil (Kochian et al. 2004). Therefore, STOP1-mediated organic acid exudation plays multiple beneficial roles including the prevention of detrimental effects of $\mathrm{Al}$ in root development, the release of $\mathrm{Pi}$ from complexes with cations for root uptake and the modification root growth. Furthermore, ALUMINUM SENSITIVE 3 (ALS3), another STOP1-target (Sawaki et al. 2009; O'Malley et al. 2016), and SENSITIVE TO ALUMINUM RHIZOTOXICITY (STAR1) also play roles in modulating root growth in response to external Pi availability (Dong et al. 2017) suggesting Al-resistance related loci might be of the outmost interest for breeding crop varieties with enhanced root morphology for topsoil exploration in acidic soils. Our recent transcriptional dissection of root responses to the conditions prevalent in acidic soils pinpoints some common regulatory hubs for tolerance to low pH, Al and Pi deficiency in Arabidopsis (Ojeda-Rivera et al. 2020), finding orthologs for these regulatory genes in crops might prove a good starting point towards finding new targets for breeding and genetic engineering strategies.

\subsection{Major QTLs associated with low Phosphorus tolerance}

Quantitative trait loci (QTLs) associated with enhanced Pi acquisition and utilization efficiency have been described in several crop species including rice, maize, bean, rapeseed and soybean (Maharajan et al. 2018). The traits related to these QTLs include root length, lateral root number, root area surface, adventitious root number, lateral root diameter and root and shoot ratio, among others (Maharajan et al. 2018). However, only a few studies have been able to identify and validate the genetic features underlying QTLs related to root architectures that are better adapted to low Pi soils. The QTL named Phosphorus Uptake 1 (Pup1) confers Pi-starvation tolerance to the rice variety Kasalath (Wissuwa et al. 2002). Further studies identified a protein kinase underlying Pup 1 QTL, this gene was named OSPSTOL 1 (PHOSPHORUS STARVATION TOLERANCE 1) (Gamuyao et al. 2012). The expression pattern of OsPSTOL 1 in low-Pi intolerant rice varieties indicates that it acts as an enhancer of early root growth by increasing the plant capacity to acquire more nutrients including $\mathrm{Pi}$ (Gamuyao et al. 2012). Although the PSTOL 1 homolog in wheat contributes to agronomically important traits like flowering time and grain size, its manipulation did not show an increase in Pi use efficiency in this species (Milner et al. 2018). Moreover, the rice landrace Wazuhophek was recently reported as a novel low Pi tolerant genotype (Swamy et al. 2019). Interestingly, Pup 1 specific markers are not present in the Wazuhophek genotype indicating the potential use of this genotype as donor of novel loci for breeding programs for low Pi tolerance. Another approach for improvement of agronomic traits includes introgression. Rye has been used as genes source for wheat improvement programs through chromosomal translocations (Jung and Seo 2014; Moskal et al. 2021). The characterization of wheat lines carrying wheat-rye translocations showed a significant positive correlation between root biomass and Pi uptake (Ehdaie et al. 2010). In the case of maize, there are data indicating that genetic introgression from the locally adapted wild teosinte (Zea mays spp.

Page 16/52 
Mexicana) into cultivated maize facilitated local adaptation of landraces to the Mexican highlands (Gonzalez-Segovia et al. 2019). Therefore, introgression of low Pi-tolerance from locally adapted wild relatives to cultivated crops seems a promising tool for breeding low-Pi tolerance in maize.

Several authors have performed an extensive literature survey of physiological and morphological QTLs in crops adapted to low Pi conditions for a detailed review we recommend the reader to consult the following references for root traits in various crops (Bovill et al. 2013; Maharajan et al. 2018; Wang et al. 2018), QTL studies of rice (Mahender et al. 2018), soybean (Kumawat et al. 2016; Zogli et al. 2017), maize (Wang et al. 2019a) and wheat (Colasuonno et al. 2021). Moreover, we have summarized the major recent QTLs related to Pi use efficiency and Pi acquisition discovered in crops in Table 1. 
Table 1

QTLs associated to phosphate deficiency tolerance with promising potential for crop improvement.

$\begin{array}{llll}\begin{array}{l}\text { Plant } \\ \text { species }\end{array} & \begin{array}{l}\text { Improved plant trait under } \\ \text { low-P }\end{array} & \text { QTL name } & \text { Reference }\end{array}$

Rice

(Oriza

sativa)
Shoot weight, root weight, total weight.

Plant height, shoot length, number of productive tillers, panicle length, dry shoot weight, root volume, yield, biomass, root/shoot ratio, seed $\mathrm{P}$ content.

Relative shoot dry weight, relative total dry weight, relative root length, relative root-to-shoot ratio.

Dry shoot weight, dry root $\quad$ GRPUUE9.16 weight, total dry weight traits.
qRST9.14

qPH8, qSL8, qNPT8, qPL8, qDSW1, qDSW8, $q R V 7, q R V 8, q S Y 8$, qBiomass 1, qBiomass8, qr1, qr8, qseedP1, qseedP7, qseedP8
(Mai et al. 2021)

(Kale et al. 2021)
qTPDE4 $4^{X B}$

(Zhang et al. 2018)

Root dried weight, P uptake Cl-bin3.04a, Cl-bin3.04b

efficiency, $P$ usage

Maize

(Zea

mays)

efficiency, seminal root

length, seminal root

number, $P$ usage efficiency,

$P$ uptake efficiency.

Root length, root diameter, surface area of fine roots, root:shoot ratio.

APase activity in root, APase activity in rhizosphere soil.
qRL8.05, qRD1.03, qRD4.05, qRD7.02, qSA2_10.03, qRS1.07, qRS3.06

BBAPR2a, BBAPR3a, HCAPR2a, HCAPR3a, HCAPR4a, HCAPR9a, HCAPR2a, HCAPR5a, HCAPR7a, HCAPR8a,

HCAPS1a-c, HCAPS3a, HCAPS5a, HCAPS9a-b, HCAPS10a

$\mathrm{H}^{+}$secretion.

nlg2228-bnlg100

qPGY4, qPGY5, qPGY7

qPLA3, qPLA4, qPLA6, qPLA9, qPLA10, qPLL2-1, qPLL2-2, qPLL6, qPLW9, qPSPAD4, qPSPAD6, qPSPAD7, qPFT2, qPFT4, qPASI4
Grain yield, leaf area, leaf length, leaf width, chlorophyll level, flowering time, anthesis silking interval.
(To et al.

2020)
(Gu et al.

2016)
(Azevedo et al. 2015)

(Qiu et al. 2014)

(Chen et al. 2011)

(Cai et al. 2012) 


\begin{tabular}{|c|c|c|c|}
\hline \multirow[t]{2}{*}{$\begin{array}{l}\text { Plant } \\
\text { species }\end{array}$} & $\begin{array}{l}\text { Improved plant trait under } \\
\text { low-P }\end{array}$ & QTL name & Reference \\
\hline & $\begin{array}{l}\text { Shoot dry weight, root dry } \\
\text { weight, total root surface } \\
\text { area, total root length, axial } \\
\text { root length, axial root } \\
\text { number. }\end{array}$ & $\begin{array}{l}\text { qSDW16-1, qSDW18-1, qSDW110-1, } \\
\text { qSDW29-1, qSDW35-1, qRDW16-1, } \\
\text { qRDW26-1, qRDW29-1, qRDW110-1, } \\
\text { qRDW210-1*, qTRSA14-1, qTRSA16-1, } \\
\text { qTRSA17-1, TRSA21-1, qTRSA110-1, } \\
\text { qTRL 11-1, qTRL 14-1, qTRL 16-1, } \\
\text { qTRL 17-1, qTRL 19-1, qTRL21-1, } \\
\text { qTRL 110-1, qARL21-7, qARL22-1, } \\
\text { qARL26-1, qARL28-1, qARL210-1, } \\
\text { qARL35-1, qARL36-1, qARL310-1, } \\
\text { qARN16-1, qARN110-1, qARN26-1, } \\
\text { qARN210-1, qARN310-1 }\end{array}$ & $\begin{array}{l}\text { (Cai et al. } \\
\text { 2012) }\end{array}$ \\
\hline \multirow[t]{7}{*}{$\begin{array}{l}\text { Wheat } \\
\text { (Triticum } \\
\text { aestivum) }\end{array}$} & $\begin{array}{l}\text { Plant height, spike length, } \\
\text { spike number per plant, } \\
\text { grain number per spike. }\end{array}$ & QPh-6D, QSI-7D.2, QSn-5A.1, QGn-7B & $\begin{array}{l}\text { (Yuan et al. } \\
\text { 2017) }\end{array}$ \\
\hline & $\begin{array}{l}\text { Root dried weight, } \\
\text { maximum root length. }\end{array}$ & $\begin{array}{l}\text { qRDW.LP-4B, qMRL.LP-2B, qMRL.LP- } \\
5 A, q M R L . L P-6 B, q M R L . L P-7 B\end{array}$ & $\begin{array}{l}\text { (Ren et al. } \\
\text { 2017) }\end{array}$ \\
\hline & Rhizosheath size. & $\begin{array}{l}\text { D_contig14507_369, } \\
\text { Excalibur_c14216_692, } \\
\text { Ex_c70232_336, GENE-2724_97, } \\
\text { BobWhite_c8579_56 }\end{array}$ & $\begin{array}{l}\text { (James et al. } \\
2016)\end{array}$ \\
\hline & Rhizosheath size. & $\begin{array}{l}\text { Tdurum_contig14482_423, } \\
\text { WSnp_EX_rep_c67296_65839761, } \\
\text { IACX5879, BS00068710_51, } \\
\text { IAAV7384, } \\
\text { BobWhite_rep_c49790_351 }\end{array}$ & $\begin{array}{l}\text { (Delhaize et } \\
\text { al. 2015) }\end{array}$ \\
\hline & $\begin{array}{l}\text { Root length, root volume, } \\
\text { root tip number, root } \\
\text { surface area, shoot dry } \\
\text { weight, root dry weight, total } \\
\text { dry weight, ratio root to } \\
\text { shoot dry weight. }\end{array}$ & $\begin{array}{l}\text { QRL.caas-6BL, QRL.caas-7BL, } \\
\text { QRL.caas-7AL, QRL.caas-7AS.2, } \\
\text { QRV.caas-7AS, QRTN.caas-2BL, } \\
\text { QRTN.caas-7BL, QRTN.caas-7AL, } \\
\text { QRTN.caas-2DL, QRTN.caas-7AS, } \\
\text { QRTN.caas-3DL, QROSA.caas-7AS, } \\
\text { QSDW.caas-6BL, QSDW.caas-6DS, } \\
\text { QSDW.caas-3AS, QSDW.caas-3DL, } \\
\text { QRDW.caas-4BS, QRDW.caas-4DS, } \\
\text { QRDW.caas-3AS, QRDW.caas-4BS, } \\
\text { QTDW.caas-4BS, QRRS.caas-4BS.1, } \\
\text { QRRS.caas-4DS, QRRS.caas-4BS.2, } \\
\text { QRRS.caas-4DS }\end{array}$ & $\begin{array}{l}\text { (Yang et al. } \\
2021 \text { ) }\end{array}$ \\
\hline & Biomass. & $\begin{array}{l}\text { Wmc44, Barc045, Nw3071, Nw2245, } \\
\text { Nw2703, Barc286, Wmc525 }\end{array}$ & $\begin{array}{l}\text { (Ryan et al. } \\
\text { 2015) }\end{array}$ \\
\hline & Plant height. & $Q P h-2 D, Q P h-4 B$ & $\begin{array}{l}\text { (Xu et al. } \\
2014)\end{array}$ \\
\hline
\end{tabular}




\begin{tabular}{|c|c|c|c|}
\hline \multirow[t]{3}{*}{$\begin{array}{l}\text { Plant } \\
\text { species }\end{array}$} & $\begin{array}{l}\text { Improved plant trait under } \\
\text { low-P }\end{array}$ & QTL name & Reference \\
\hline & \multirow{2}{*}{$\begin{array}{l}\text { Shoot length, thousand } \\
\text { kernel weight, kernel weight } \\
\text { per spike, total spiklet } \\
\text { number per spike, sterile } \\
\text { pikelet number per spike, } \\
\text { harvest index, spikelet } \\
\text { compactness, grain } \\
\text { nitrogen concentration, } \\
\text { straw nitrogen uptake, N } \\
\text { utilization efficiency for } \\
\text { grain yield, plant height, } \\
\text { maximal root length, axial } \\
\text { root number, stem and leaf } \\
\text { dry weight, seedling dry } \\
\text { weight, stem and leaf P } \\
\text { utilization efficiency, root P } \\
\text { utilization efficiency, shoot } \\
\text { P utilization efficiency, stem } \\
\text { and leave P content. }\end{array}$} & $\begin{array}{l}\text { QSI-2D, QTkw-3B, QTkw-3B.1, QTkw- } \\
\text { 4D, QKWS-6A, QTSS-7A, QSSS-2D, QHi- } \\
\text { 4B, QSCn-2D, QGnC-6A, QSnup-5A.1, } \\
\text { QNUtEGY-4D, QNUtEGY-6A, }\end{array}$ & \multirow[t]{2}{*}{$\begin{array}{l}\text { (Zhang, Wang } \\
\text { 2015) }\end{array}$} \\
\hline & & $\begin{array}{l}\text { QPH-1D, QPH-3A, QPH-3B.2, QPH-5D, } \\
\text { QPH-7B.1, QRL-1A, QRL-5B, QRL-7A, } \\
\text { QRN-2B.1, QRN-2B.2, QSLDW-1D, } \\
\text { QSLDW-4D, QSLDW-5D-1, QSDW-1D, } \\
\text { QSDW-3B, QSDW-5D, QSLPU-2B, } \\
\text { QSLPU-5A.7, QRPU-4B, QRPU-7B, } \\
\text { QSPU-2B, QSLPC-2B, QSLPC-3A }\end{array}$ & \\
\hline \multirow[t]{3}{*}{$\begin{array}{l}\text { Soybean } \\
\text { (Glycine } \\
\text { max) }\end{array}$} & $\begin{array}{l}\text { P use efficiency, root dry } \\
\text { weight, total dry weight, } \\
\text { plant height, P } \\
\text { concentration. }\end{array}$ & $q 4-2$ & $\begin{array}{l}\text { (Zhang et al. } \\
2016 \text { ) }\end{array}$ \\
\hline & $\begin{array}{l}\text { Individual seed weight, } \\
\text { intact pod weight, seed } \\
\text { volume, seed protein. }\end{array}$ & $\begin{array}{l}\text { SeedwtQTL4.1, SeedwtQTL4.3, } \\
\text { SeedwtQTL6.1, PodwtQTL4.2, } \\
\text { VolQTL6.2, ProtQTL20.1 }\end{array}$ & $\begin{array}{l}\text { (Hacisalihoglu } \\
\text { et al. 2018) }\end{array}$ \\
\hline & 100-seed weight. & qSW17-2, & $\begin{array}{l}\text { (Wu et al. } \\
2020)\end{array}$ \\
\hline \multirow[t]{2}{*}{$\begin{array}{l}\text { Barley } \\
\text { (Hordeum } \\
\text { vulgare) }\end{array}$} & $\begin{array}{l}\text { Grain } P \text { concentration, } \\
\text { straw } P \text { concentration, plant } \\
P \text { concentration, grain } P \\
\text { uptake, straw } P \text { uptake, } \\
\text { plant } P \text { uptake, grain } P \\
\text { utilization efficiency, straw } \\
P \text { utilization efficiency, plant } \\
P \text { utilization efficiency, grain } \\
\text { yield, straw yield, dry matter. }\end{array}$ & $\begin{array}{l}\text { Qgpc.sau-3H, Qspc.sau-3H, Qspc.sau- } \\
\text { 7H, Qpc.sau-3H, Qgpup.sau-1H, } \\
\text { Qspup.sau-3H, Qpup.sau-1H, } \\
\text { Qgpue.sau-3H, Qspue.sau-7H, } \\
\text { Qpue.sau-3H, Qgy.sau-5H, 7H, } \\
\text { Qsy.sau-3H, Qdm.sau-3H, Qdm.sau- } \\
\text { 5H, Qdm.sau-7H }\end{array}$ & $\begin{array}{l}\text { (Gao et al. } \\
2020)\end{array}$ \\
\hline & $\begin{array}{l}\text { Total root length, total root } \\
\text { surface area, total root } \\
\text { volume, adventitious root } \\
\text { length, adventitious root } \\
\text { surface area, adventitious } \\
\text { root volume, lateral root } \\
\text { length, lateral root surface } \\
\text { area, lateral root volume, } \\
\text { lateral root length. }\end{array}$ & $\begin{array}{l}\text { Qtrl.sau-7H.01, Qtrl.sau-7H.02, } \\
\text { Qtrl.sau-4H.01, Qtrsa.sau-4H.01, } \\
\text { Qtrsa.sau-7H.01, Qtrsa.sau-4H.02, } \\
\text { Qtrsa.sau-3H.01, Qtrv.sau-3H.01, } \\
\text { Qarl.sau-4H.01, Qarl.sau-3H.01, } \\
\text { Qarl.sau-3H.02, Qarsa.sau-4H.01, } \\
\text { Qarsa.sau-3H.01, Qarv.sau-4H.01, } \\
\text { QIrl.sau-2H.01, Qlrsa.sau-4H.01, } \\
\text { Qlrsa.sau-2H.01, Qlrv.sau-3H.01, } \\
\text { QIrl.sau-4H.01, QIrl.sau-2H.01 }\end{array}$ & $\begin{array}{l}\text { (Guo et al. } \\
\text { 2018) } \\
\text { (Shang-Qing } \\
\text { et al. 2018) }\end{array}$ \\
\hline
\end{tabular}




\begin{tabular}{|c|c|c|c|}
\hline $\begin{array}{l}\text { Plant } \\
\text { species }\end{array}$ & $\begin{array}{l}\text { Improved plant trait under } \\
\text { low-P }\end{array}$ & QTL name & Reference \\
\hline $\begin{array}{l}\text { Sorghum } \\
\text { (Sorghum } \\
\text { bicolor) }\end{array}$ & $\begin{array}{l}\text { Grain yield, root diameter, } \\
\text { surface area of fine roots } \\
\text { between } 1-2 \mathrm{~mm} \text { in } \\
\text { diameter. }\end{array}$ & $\begin{array}{l}\text { Gy-1, Gy-3, Gy-4. 1, Gy-4.2, Gy-6.1, Gy- } \\
\text { 6.2, Gy-6.3, Gy-9, SA2-3, SA2-8, RD-5, } \\
\text { Gy/SA2-3, RD/SA2-2, Gy/RD-7 }\end{array}$ & $\begin{array}{l}\text { (Bernardino et } \\
\text { al. 2019) }\end{array}$ \\
\hline $\begin{array}{l}\text { Bean } \\
\text { (Phaseolus } \\
\text { vulgaris) }\end{array}$ & $\begin{array}{l}\mathrm{N} \text { fixation, yield } \\
\text { components, phenological, } \\
\text { photosynthetic. }\end{array}$ & $\begin{array}{l}\text { \%Ndfa7.1, TNdfa7.1, TNdfa8.1, } \\
\text { TNdfs8.1, SdN2.1, SdN2.2, SdN7.1, } \\
\text { SdN_ha 2.1, SdN_ha 7.1, SdCN2.1, } \\
\text { SdCN7.1, PHI4.1, PHI5.1, PHI5.2, } \\
\text { SBH2.1, SBH5.1, SBH11.2, SdC4.1, } \\
\text { SdC6.1, Yd2.1, Yd7.1, Yd7.2, PNA2.1, } \\
\text { PNA4.1, PNA4.2, PNA6.1, SdNA2.1, } \\
\text { SdNA6.1, SdNA6.2, 100SdW2.1, } \\
\text { 100SdW6.1, 100SdW6.2, 100SdW9.1, } \\
\text { 100SdW9.2, DF4.1, DF5.1, DF5.2, } \\
\text { DF5.3, DF5.4, DF11.1, DF11.2, } \\
\text { SCMR_f3.1, SCMR_f3.2, SCMR_f4.1, } \\
\text { SCMR_f6.1, SCMR_f6.2, SCMR_f6.3, } \\
\text { SCMR_m2.1, SCMR_m6.1, } \\
\text { SCMR_m6.2, FVFM11.3 }\end{array}$ & $\begin{array}{l}\text { (Diaz et al. } \\
2017 \text { ) }\end{array}$ \\
\hline \multicolumn{4}{|c|}{$\begin{array}{l}\text { The studies described were limited to experiments carried out under greenhouse or field conditions. } \\
\text { Abbreviations: P, phosphorus; } N \text {, nitrogen. *These QTLs are changed according to developmental } \\
\text { stage. }\end{array}$} \\
\hline
\end{tabular}

\section{Novel Strategies To Produce Phosphorus Efficient Plants}

The ultimate end of characterizing plant responses to $\mathrm{Pi}$ availability and dissecting the molecular regulators orchestrating these responses is to accelerate the development of crop varieties that are more efficient in Pi uptake and Pi use efficiency and, thus, contribute to the development of more sustainable and resilient food systems. Therefore, potential routes include changes in the roots system architecture, improvement of $\mathrm{P}$ uptake and remobilization, and remodeling of rhizosphere-microbial associations. In this section some examples of these routes are summarized and novel strategies proposed. A summary of perspectives for targeted improvement of low-Pi tolerant plants is presented in Figure 5.

\subsection{Genes for the modulation of Phosphorus metabolism}

Examples of breeding efforts are found in the introgression or transfer of Pi-uptake and Pi use-efficiency genes/alleles from Pi-starvation tolerant landraces or traditional varieties into modern crop varieties. One of the best examples is the manipulation of the OsPstol 1 gene from the Pi-starvation tolerant Kalasath rice, which significantly enhanced grain yield when overexpressed in Pi-starvation intolerant rice varieties grown under Pi-deficient soil conditions (Gamuyao et al. 2012).

In the context of genetic engineering, the heterologous expression of bacterial genes to promote Pi uptake from alternative Pi sources seem very promising. Transgenic Arabidopsis plants expressing bacterial phytases (PaPhyC and 168phA) can use phytic acid as a Pi source without any negative physiological 
effects on plant development and germination (Valeeva et al. 2018). Furthermore, reduction of phytic acid content in grain has been also proposed as a solution that might contribute to reduce Pi-based fertilizer use by preventing excessive removal of $P$ from the soil (Perera et al. 2018). Phytic acid is a plant Pistorage molecule that accumulates in grain and is not digested by humans or livestock, removal of rootacquired Pi from field in the form of phyic acid in grain accounts for more than $50 \%$ of the worldwide application of Pi-based fertilizer (Raboy 2001). The finding and disruption of a SULTR-like phosphorus distribution transporter, SPDT, that is expressed in the rice nodes and controls the allocation of phosphorus to the grain, resulted in the production of knock-out lines that present reduced phytate content in grain without compromising yield and seed germination (Yamaji et al. 2017). This finding proved that the reduction of phytic acid is a feasible task in crops trough the knockout or knock-down of genes coding for grain SPDT-like Pi-translocator proteins. Knocking out IPK1 and ITPK1 kinase-coding genes in crops like maize, rice and wheat also resulted in the production of lines with reduced accumulation of phytic acid (Shi et al. 2003; Shukla et al. 2009; Ali et al. 2013; Aggarwal et al. 2018).

The engineering of transgenic plants that express the $p t x D$ gene from Pseudomonas stutzeri, which codes for an oxidoreductase that oxidizes phosphite to Pi, resulted in the production of plants that can use phosphite, the reduced and non-plant metabolizable form of $P$, and require 30-50\% less $P$ input when fertilized with phosphite under greenhouse conditions (López-Arredondo and Herrera-Estrella 2012). More recently, this technology has been applied to the production of rice, maize and cotton plants that can be fertilized with phosphite as the sole source of P (Nahampun et al. 2016; Manna et al. 2016; Pandeya et al. 2018; Lopez-Arredondo et al., 2021). One of the main advantages of phosphite-fertilization technology is that it suppresses weed growth and enables transgenic crops to outcompete aggressive and glyphosateresistant weeds while, at the same time, phosphite provides Pi fertilization that can only be harnessed by ptxD-expressing plants (López-Arredondo and Herrera-Estrella 2012; Pandeya et al. 2018).

\subsection{Deployment of symbionts to boost phosphate uptake}

Root colonization of microbiota and endophytic fungi, which improves plant fitness under Pi starvation conditions in Arabidopsis, has been demonstrated to be mediated by AtPHR1 (Hiruma et al. 2016; Castrillo et al. 2017). These findings hint at the deployment of specific consortiums of microbes and endophytes as tools to improve Pi nutrition in plants and at the fine tuning of PHR1-mediated regulation in crops to enhance root colonization by benefiting beneficial consortiums. It was recently demonstrated that inhibition of suberin deposition by microbiota facilitates plant nutrient uptake (Salas-González et al. 2021). Because microbiota-directed inhibition of suberin depositions occurs via the inhibition of ABA signaling (Salas-González et al. 2021), these findings hint at the downregulation of abscisic-acid synthesis genes in crops to prevent suberization and promote association with beneficial consortiums of root microbiota.

A well-known fact is that root symbiosis with AMF can contribute to enhance plant nutrition. In the case of maize, biotic-mediated $\mathrm{Pi}$ uptake is a promising tool to enhance Pi uptake as it has been shown that symbiotic Pi uptake by AMF accounts for up to one third of grain yield in rain-fed, medium input subtropical fields (Ramírez-Flores et al. 2020). AMF are effective in foraging Pi for the plant as these 
symbionts can spread beyond the rhizosphere Pi-depleted zones and provide Pi that otherwise would be inaccessible for the root system (Chen and Liao 2017). Phosphate transporters induced by AMF in rice (OsPT11/13) and soybean (GmPT7/10/11) are evidence of plant Pi uptake at this symbiotic interface (Chen and Liao 2017). Up to 70\% of Pi uptake in rice is symbiotically acquired, corroborating the relevance of AMF in crops (Yang et al. 2012). Interestingly, high Pi fertilizer application can reduce the percentage of root colonization and decrease AMF biomass (Smith et al. 2011; López-Arredondo et al. 2014) which indicates that AMF might only play a Pi-uptake enhancing role when Pi conditions are limiting. Further investigation on the role of AMF in "high Pi" soils is required to sort out this controversy, however, knowing the genetic elements that regulate the activation/deactivation of the symbiotic $\mathrm{Pi}$ uptake pathways could lead to the development of plant varieties that could maintain AMF symbiosis independently of the Pi status in the plant. Undoubtedly, because limited Pi availability is a major constrain in most croplands, deployment of AMF remains a valuable use to enhance crop Pi uptake.

\subsection{Genome editing approaches}

CRISPR/Cas (Clustered regularly interspaced short palindromic repeats/CRISPR-associated Cas) has emerged as one of the most promising systems to alter in a precise way the genome of any organism (Khatodia et al. 2016; Wang et al. 2019b; Zhao et al. 2019). This gene editing system was built on the basic mechanism of the adaptive immune system of bacteria and archaea against invading nucleic acids such as viruses. It basically consists of a guide RNA (gRNA) and a CRISPR-associated endonuclease protein (e.g. Cas9) (Jiang and Doudna 2017). Recently, the CRISPR/Cas system has been significantly improved, allowing simultaneous edition of multiple sites of coding and regulatory sequences, as well as improved delivery methods of the assembled Cas 9 enzyme directly into the target cells without the need for stable integration of transgenes (for review see Arora and Narula 2017; Jaganathan et al. 2018). Furthermore, Cas9 variants deactivated at one (nickase Cas9, nCas9) or the two (dead or deactivated Cas9, dCas9) nuclease domains that interact with other functional components expand the application of the CRISPR/Cas system beyond editing. Both nCas9 and dCas9 maintain their ability to associate with a gRNA, recognize its target sequence in the genome, and be associated by Watson-Crick interactions without producing any double-strand breaks. Furthermore, the availability of multiple Cas proteins with different properties and size from different bacterial species (e.g. Cas9, Cas12, Cpf1, CasPhi) has broaden the potential of this technology (see Jaganathan et al. 2021). Therefore, the CRISPR/Cas system has been utilized to induce insertions and deletions, base replacement and base editing, activation and repression of specific genes and epigenetic modifications which is now paving the progress of plant biology, agriculture, and many other scientific fields.

CRISPR/Cas technologies offer a series of advantages; for example, in contrast to the transgenic approach in which DNA expression cassettes are randomly inserted in the genome and may cause pleiotropic phenotypes, genome editing approaches allow a precise design of the desired trait. Moreover, since edited varieties may be generated via selectable marker-independent methods (transgene-free), they are less subjected to acceptability and regulatory issues compared to transgenics, so the resulting events may be directly incorporated into breeding programs and commercialized as feed and food. Nevertheless, 
"off-targets" mutations and some technical hurdles for the successful implementation of CRISPR/Cas systems have been extensively discussed (see Montecillo et al. 2020). Thus, the use of the CRISPR/Cas system has boosted the study of plant responses to diverse abiotic stresses including drought stress, $\mathrm{K}$ and $\mathrm{N}$ deficiencies and to a lesser extent on $\mathrm{P}$ starvation. Works have been performed specially on rice, maize, and tomato to cite a few (see (Jaganathan et al. 2018)). However, most of these studies are limited to the functional validation of already reported genes in which knockouts are described, and thus, provide the proof-of-concept for future crop improvement. Besides some examples in which CRISPR/Cas was used to assess the biological function of $P$ starvation response-related gene orthologues, to our knowledge there are no reports yet on the use of the CRISPR/Cas system for the improvement of low $P$ tolerance in crops. This technology, for instance, was used to generate deletion mutants of the AtPHO1 homolog in tomato, S/PH01;1, which displayed typical characteristics of Pi starvation, shorter and redder leaves than the wild-type control as previously reported for Arabidopsis (Zhao et al. 2019). CRISPR/Cas9 was also used to generate allelic variants of HvITPK1 (Inositol trisphosphate 5/6 kinase 1) in barley (Hordeum vulgare) with the purpose of lowering phytic acid levels (Vlčko and Ohnoutková 2020). As previously mentioned, and illustrated in Figure 4b, ITPKs participate in the sequential phosphorylation of IP (inositol polyphosphate) to produce phytic acid and have been proposed to play important roles in abiotic stress responses including drought and salinity (Niu et al. 2008; Marathe et al. 2018). Interestingly, barley ITPK1 allelic variants showed salinity stress tolerance, thus posing new questions on the role of these enzymes on general abiotic stress signaling. A similar approach was implemented using TALEN and CRISPR/Cas9 to lower phytic acid synthesis by impairing ZmIPK1 in maize (Shukla et al. 2009; Liang et al. 2014). Being ethylene an important modulator for both local and systemic responses to low $P$, the role of OsACS1 (1-aminocyclopropane-1-carboxylic acid synthase) and OsACS2 was investigated in rice by taking advantage of CRISPR/Cas9 (Lee et al. 2019). Both were found involved in remodeling Arabidopsis root system architecture, transcriptional regulation of $\mathrm{Pi}$ starvation responsive genes and $\mathrm{Pi}$ homeostasis.

On the other hand, reports on $\mathrm{N}$ metabolism provide clear examples of the utility and effectiveness of this technology, thus, suggesting it is a plausible strategy to speed up targeted crop breeding for low $P$ tolerance. An interesting case study is the NRT1.1 nitrate transporter in rice. Previously, a single nucleotide polymorphism consisting of $\mathrm{C} / \mathrm{T}$ (Thr327Met) change was associated with nitrogen use efficiency improvement (Hu et al. 2015). Therefore, by using and optimizing the CRISPR/Cas9 system, the precise base-editing to generate $\mathrm{C} / \mathrm{T}$ replacement at this location (Thr327Met) in NRT1.1B was successfully done (Lu and Zhu 2017). Furthermore, Li and co-workers (2018), using CRISPR/Cas9 replaced the complete japonica NRT1.1B allele by the high $\mathrm{N}$ use efficiency indica allele in only one generation (Li et al. 2018), which by traditional introgression would take between 4 to 6 generations, proving the versatility and power if this technology to improve agricultural traits.

\section{Perspectives}

Current agricultural food systems are built on improved crop varieties and the extensive use of agrochemicals. For years, breeders have taken advantage of natural or induced genetic diversity in order 
to generate improved varieties. Clear examples of these efforts can be seen in improved rice varieties that have undergone drastic changes in plant architecture and grain yield and, thus, have sustained the Green Revolution. These varieties now provide $35-60 \%$ of dietary calories to more than $50 \%$ of the global population (Peng et al. 2021). However, this process is slow and its application on crop low Pi tolerance have not yet produced the varieties needed to significantly reduce the application of P-fertilizers. By exploiting the promises of novel approaches such as CRISPR/Cas and synthetic biology it would be possible speed up the creation of the genetic diversity that is required for breeding purposes, and even to enrich this diversity beyond what we naturally though possible.

Transcription factors represent promising candidates for improving resistance to multiple environmental stresses because they control growth and development and orchestrate plant responses to various abiotic stresses and may present overlapping functions (Patikoglou and Burley 1997; Lindemose et al. 2013). Several transcription factors belonging to different families have been described to play crucial roles in modulating low Pi starvation responses and crosstalk with hormones in crops including MYB62 (regulating the cross-talk between Pi and gibberellic Acid) (Devaiah et al. 2009), ETC1 (important in favoring higher root hair density under low P conditions) (Savage et al. 2013), and MYB2 (involved in mediating Pi starvation responses through miR399f) to cite some (Baek et al. 2013) (see Jyoti et al. 2019). In recent years, regulatory networks composed of key transcription factors controlling plant responses to P starvation have been identified (Shi et al. 2021). Interestingly, Shi and co-workers (2021) recently reported a network of 266 transcription factors underlying low $P$ responses in rice in the context of AMF symbiosis. Importantly, the network is centered in PHR family transcription factors, widely known to control P starvation adaptive responses in plants (Figure 4a), and is enriched in Pi starvation, $\mathrm{N}$ metabolism, and chromatin remodeling related transcription factors. Moreover, it captured transcription factors controlling mycorrhizal symbiosis and hormone signaling pathways (i.e. ethylene, jasmonic acid, auxins) reported previously such as ARF12, ARF25, MYC2, among others (Shi et al. 2021). These findings represent emerging opportunities to modulate and remodel in a precise way the activity of specific nodes of regulation orchestrating low $P$ responses at specific organs or cell types, and at specific stages of development when the plant requires $P$ the most. Such level of regulation involving a crosstalk between $P$ metabolism, mycorrhizal symbiosis, and hormone signaling suggests that highly complex and intricate regulatory mechanisms that can be only studied in a more comprehensive way by applying CRISPR/Cas multiplexed approaches rather than manipulating a single gene at a time. These studies should allow genome-wide transcriptional reprogramming in crop plants for breeding purposes. We presented in Figure 3 gene regulons composed of key transcription factors, protein regulators, and microRNAs controlling Pi homeostasis in plants, which can serve as the basis to remodel Pi starvation responses in crops. Likewise, engineering plant associated microbial communities has been proposed as an effective and complementary strategy to improve Pi use efficiency, as microorganisms can serve as biostimulants, biofertilizers, and biocontrol factors (Ke et al., 2021) (Figure 5).

Due to the crosstalk between hormone signaling and the regulation of $\mathrm{P}$ starvation responses, it is plausible to think that a tight modulation of low $\mathrm{P}$ responses can be achieved by fine-tuning both internal and secreted hormone levels through CRISPR/Cas. Strigolactones are phytohormones involved in 
regulating the growth of primary and lateral roots; upregulation of strigolactone synthesis and rootexudation under Pi limiting conditions have been shown to favor AMF symbiosis (Mayzlish-Gati et al. 2012; Sun et al. 2014; Santoro et al. 2020). However, high levels of strigolactones can also promote the germination of weeds, for example Striga, which are very well known to threaten crop productivity specially in African fields (Khosla and Nelson 2016; Yacoubou et al. 2021). Therefore, by fine-tuning strigolactone levels, for instance by generating CRISPR/Cas allelic variants, one would be able to improve crop fitness by modulating root traits and AMF symbiosis in benefit of low-Pi tolerance while avoiding Striga germination. CRISPR/Cas edited rice lines to disrupt CCD7 (CAROTENOID CLEAVAGE DIOXYGENASE 7), an enzyme involved in a limiting step in strigolactone biosynthesis, have been already been reported (Butt et al. 2018). Interestingly, CCD7-edited lines showed reduced height, increased tiller production, and reduced exudation of strigolactones compared to the wild type. However, no total yield was reported and the effect of CCD7-targeted mutagenesis on plant Pi starvation responses and association with AMF was not addressed. Further studies are required to test the effect of strigolactone downregulation in AMF formation and Pi nutrition under Pi-limiting conditions.

As mentioned before, three residues (K325, H328, R335) in the coiled-coil (CC) domain of AtPHR1 have been identified to be essential for binding AtSPX1. Interestingly, mutation of these residues disrupts AtSPX-binding without affecting AtPHR1's ability to bind its target sequence results in constitutive activation of Pi starvation responses (Ried et al. 2021). Now, with the possibility of doing specific nucleotide base replacements with CRISPR/Cas, it would be interesting to test how specific changes on these three PHR1 ${ }^{\mathrm{KHR}}$ residues (or different combinations of them) may modulate the strength and speed of the low-Pi stress responses in crop species. Likewise, as IP molecules have been proven to be essential to stabilize SPX proteins structure enabling them to interact with Pi-homeostasis regulators in eukaryotes (Wild et al. 2016), the possibility of fine-tuning IP-molecules biosynthesis, $I_{6}, I_{7}$ and $I_{8}$ for instance,remains an interesting perspective for future breeding. Given the essential role of IP molecules as cofactors of auxin and jasmonic acid sensing complexes and the crosstalk with plant Pi status, a possibility remains that by modifying the balance of $I P$-signaling molecules like $\mathbb{I P}_{8}, \mathrm{IP}_{5}$, and $\mathrm{IP}_{6}$, for example, stress responses can be finely modulated at a system level.

CRISPR/Cas genome-editing could also facilitate the production of crops with a significantly reduced content of phytic acid by simultaneously knocking-out orthologs of the rice SPDT grain phytate translocator and phytate synthase coding genes, like IPK1 and ITPK1, in crops like maize, rice and wheat (Figure 5). Because single knock-out lines of these genes present reduced phytic acid accumulation in grain (Shi et al. 2003; Shukla et al. 2009; Ali et al. 2013; Yamaji et al. 2017; Aggarwal et al. 2018), this remains a promising perspective to significantly prevent excessive $P$ removal from the field at the time of harvest and reduce phytic acid accumulation in grain, which is not assimilated by humans and animals. Moreover, genomic and transcriptomic characterization of gene-regulation networks in species that are adapted to environments with extreme Pi limitation, like the Proteaceae, should provide insights into the re-wiring of phospholipid metabolism, possibly through editing of promoters of crop genes related to the promotion of phospholipid substitution, without compromising photosynthesis as it happens in the 
Proteaceae (Lambers et al. 2012). In this context, introgression of genetic material from low-Pi adapted landraces to elite materials remains a valuable tool that enables breeding of low-Pi tolerant materials without compromising yield (Gamuyao et al. 2012), which indicates that traditional breeding and QTLs should not be ignored, rather they should be integrated with newer technologies to develop low-Pi tolerant crops.

The transcription factor STOP1 controls an interesting regulatory network that modulates root transcriptional adaptation to the conditions present in acidic soils, including low $\mathrm{pH}$, Al toxicity and low $\mathrm{Pi}$ availability (Sawaki et al. 2009; Ojeda-Rivera et al. 2020). Some of the STOP1-targets include organic acid transporters that mediate Pi solubilization and, in the particular case of $A L M T 1$, mediate root growth in response to low Pi availability (Balzergue et al. 2017; Mora-Macías et al. 2017). Because the STOP1binding site has been identified and we have recently shown that the activation of STOP1-targets correlates with its nuclear accumulation (Ojeda-Rivera et al. 2020), the CRISPR/Cas9 system could be used to edit the promoter sequences of STOP1-target genes to modulate and re-wire root organic-acid synthesis and exudation and thus, contribute to designing smart crops that are able to thrive and have a root system architecture better adapted to acidic soils with low-Pi availability. In this context, another interesting candidate gene is the root specific HRS1 (Hypersensitivity to low Pi-elicited primary root shortening 1) transcription factor, involved in modulating the primary root growth in response to $\mathrm{Pi}$ starvation only when in presence of nitrate (Liu et al. 2009; Medici et al. 2015). Therefore, as this transcription factor helps integrate signaling responses to both $\mathrm{N}$ and $\mathrm{Pi}$ signals in the root tip (Medici et al. 2015), it provides an interesting perspective to achieve the coordinated modulation of plant responses to both stresses. The design of biosensor molecules might also contribute to achieve these types of strategies by adding an external predictable and controllable switch to the system. The infiltration into plant cells of nanosensors wrapped into single-walled carbon nanotubes has already been used for different purposes including detection of external nitroaromatic compounds (Wong et al., 2017), arsenic (Lew et al., 2021), auxins (Ang et al., 2021), and $\mathrm{H}_{2} \mathrm{O}_{2}$ in stressed plants (Lew et al., 2020).

Furthermore, a genetically encoded auxin biosensor was recently reported that allows the direct, rapid and real-time monitoring of auxin levels in individual cells and within cell compartments during the plant's life cycle (Herud-Sikimic et al., 2021). This sensor is based on the rational engineering of a tryptophan repressor from $E$. coli and although originally designed for in planta visualization of auxin concentration, it can be easily incorporated for the design of more biotechnological applications.

Now that complex networks of regulation controlling Pi starvation responses are being elucidated and versatile CRISPR/Cas gene editing strategies can be implemented with the help of the latest and more sophisticated on-development computational resources, we might think on crop improvement based on more rational designs that can be systematically generated and evaluated (Liu and Stewart 2015). In this context, synthetic biology approaches that integrate and take advantage of multiple disciplines for the redesign and rewiring of genetic connections might be a useful asset (Kassaw et al. 2018; Pouvreau et al. 2018). This will help removing inefficiencies naturally associated with these processes while optimizing the essential components towards the desired trait. As stated by Medford and Prasad (2014), this type of 
approaches will help "not only uncover the natural genetic circuits behind complex gene regulations in plants, but we could also design traits that are new to evolution and beneficial to humanity" (Medford and Prasad 2014).

These previously mentioned perspectives can be accomplished by thoroughly harnessing all the power and potential from emerging technologies. Short-read and long-read sequencing technologies should coordinately aid in deciphering the genomes and transcriptomes of species adapted to extreme $\mathrm{Pi}$ scarcity and provide new gene pools and gene regulatory networks for low-Pi tolerance. Single-cell technologies will be crucial to decipher the hierarchical role of molecular regulators in such gene networks. Developments in proteomics, like the recent application of nanopores to determine protein fingerprinting (Lucas et al. 2021), altogether with high throughput metabolomic characterization should aid defining the phenotypic profile of the Pi-efficient crop varieties. The development of efficient and standardized tissue-culture-independent gene editing systems will be key to enable gene replacement and genome editing of crop plants which will ultimately help plant scientists and breeders to fine-tune plant $\mathrm{Pi}$ metabolism and root systems to boost Pi foraging and Pi-use efficiency. Artificial intelligence approaches, like machine learning (Esposito et al. 2020), could be applied to detect and predict low-Pi tolerancerelated genes and traits. Close collaboration of the scientific community and plant breeders with industry, policy and decision makers and government agencies must be promoted to guarantee technology transfer, a favorable public perception and fair distribution of crop materials to ultimately help us to achieve sustainable crop Pi nutrition and food security.

\section{Declarations}

\section{Authors contribution}

DL-A defined the concept, outlined the contents and supervised the entire work. All authors conducted literature review and wrote different sections of the manuscript. JOO-R generated the first draft of the manuscript. DLL-A and JOO-R designed figures; GA-J and H-RN-G curated data and prepared able. DLL-A critically revised the work and finalized the manuscript. All authors reviewed and approved the final manuscript.

\section{Acknowledgments}

We thank Dr. Luis Herrera-Estrella for valuable comments on the manuscript. This work was supported partially by USDA-NIFA 20196702929912, USDA-ARS 21A546, and Cotton Incorporated 21-844 grants. We are grateful to the State of Texas' Governor's University Research Initiative (GURI)/Texas Tech University support.

\section{Ethics declarations}

\section{Competing interests}

The authors declare they have no financial interests. 


\section{References}

1. Aggarwal S, Kumar A, Bhati KK et al (2018) RNAi-Mediated Downregulation of Inositol Pentakisphosphate Kinase (IPK1) in Wheat Grains Decreases Phytic Acid Levels and Increases Fe and Zn Accumulation. Front Plant Sci 0:259. https://doi.org/10.3389/FPLS.2018.00259

2. Ajmera I, Charlie Hodgman T, Lu C (2019) An integrative systems perspective on plant phosphate research. Genes (Basel) 10:139

3. Alewell C, Ringeval B, Ballabio C et al (2020) Global phosphorus shortage will be aggravated by soil erosion. Nat Commun 2020111 11:1-12. https://doi.org/10.1038/s41467-020-18326-7

4. Ali N, Paul S, Gayen D et al (2013) Development of Low Phytate Rice by RNAi Mediated Seed-Specific Silencing of Inositol 1,3,4,5,6-Pentakisphosphate 2-Kinase Gene (IPK1). PLoS ONE 8:e68161. https://doi.org/10.1371/JOURNAL.PONE.0068161

5. Ang MC-Y, Dhar N, Khong DT et al (2021) Nanosensor Detection of Synthetic Auxins In Planta using Corona Phase Molecular Recognition. ACS Sensors 6:3032-3046. https://doi.org/10.1021/ACSSENSORS.1C01022

6. Arora L, Narula A (2017) Gene Editing and Crop Improvement Using CRISPR-Cas9 System. Front Plant Sci 0:1932. https://doi.org/10.3389/FPLS.2017.01932

7. Asimov I (1974) Asimov on chemistry. 267

8. Awai K, Maréchal E, Block MA et al (2001) Two types of MGDG synthase genes, found widely in both 16:3 and 18:3 plants, differentially mediate galactolipid syntheses in photosynthetic and nonphotosynthetic tissues in Arabidopsis thaliana. Proc Natl Acad Sci U S A 98:10960-10965. https://doi.org/10.1073/pnas.181331498

9. Azevedo GC, Cheavegatti-Gianotto A, Negri BF et al (2015) Multiple interval QTL mapping and searching for PSTOL1 homologs associated with root morphology, biomass accumulation and phosphorus content in maize seedlings under low-P. BMC Plant Biol 2015151 15:1-17. https://doi.org/10.1186/S12870-015-0561-Y

10. Baek D, Kim MC, Chun HJ et al (2013) Regulation of miR399f transcription by AtMYB2 affects phosphate starvation responses in Arabidopsis. Plant Physiol 161:362-373. https://doi.org/10.1104/pp.112.205922

11. Balzergue C, Dartevelle T, Godon C et al (2017) Low phosphate activates STOP1-ALMT1 to rapidly inhibit root cell elongation. Nat Commun 8:15300. https://doi.org/10.1038/ncomms 15300

12. Bari R, Pant BD, Stitt M, Scheible WR (2006) PHO2, microRNA399, and PHR1 define a phosphatesignaling pathway in plants. Plant Physiol 141:988-999. https://doi.org/10.1104/pp.106.079707

13. Barragán-Rosillo AC, Peralta-Alvarez CA, Ojeda-Rivera JO et al (2021) Genome accessibility dynamics in response to phosphate limitation is controlled by the PHR1 family of transcription factors in Arabidopsis. Proc Natl Acad Sci 118. https://doi.org/10.1073/PNAS.2107558118

14. Bates TR, Lynch JP (1996) Stimulation of root hair elongation in Arabidopsis thaliana by low phosphorus availability. Plant, Cell Environ 19:529-538. https://doi.org/10.1111/j.1365- 
3040.1996.tb00386.x

15. Batjes NH (1997) A world dataset of derived soil properties by FAO-UNESCO soil unit for global modelling. Soil Use Manag 13:9-16. https://doi.org/10.1111/J.1475-2743.1997.TB00550.X

16. Bernardino KC, Pastina MM, Menezes CB et al (2019) The genetic architecture of phosphorus efficiency in sorghum involves pleiotropic QTL for root morphology and grain yield under low phosphorus availability in the soil. BMC Plant Biol 2019191 19:1-15. https://doi.org/10.1186/S12870-019-1689-Y

17. Bonsdorff E (2021) Eutrophication: Early warning signals, ecosystem-level and societal responses, and ways forward. Ambio 50:753-758. https://doi.org/10.1007/s13280-020-01432-7

18. Bovill WD, Huang CY, McDonald GK (2013) Genetic approaches to enhancing phosphorus-use efficiency (PUE) in crops: Challenges and directions. Crop Pasture Sci 64:179-198. https://doi.org/10.1071/CP13135

19. Bustos R, Castrillo G, Linhares F et al (2010) A Central Regulatory System Largely Controls Transcriptional Activation and Repression Responses to Phosphate Starvation in Arabidopsis. PLoS Genet 6:e1001102. https://doi.org/10.1371/journal.pgen.1001102

20. Butt $\mathrm{H}$, Jamil M, Wang JY et al (2018) Engineering plant architecture via CRISPR/Cas9-mediated alteration of strigolactone biosynthesis. BMC Plant Biol 2018181 18:1-9. https://doi.org/10.1186/S12870-018-1387-1

21. Cai H, Chen F, Mi G et al (2012) Mapping QTLs for root system architecture of maize (Zea mays L.) in the field at different developmental stages. Theor Appl Genet 20121256 125:1313-1324. https://doi.org/10.1007/S00122-012-1915-6

22. Cai H, Chu Q, Yuan L et al (2011) Identification of quantitative trait loci for leaf area and chlorophyll content in maize (Zea mays) under low nitrogen and low phosphorus supply. Mol Breed 2011301 30:251-266. https://doi.org/10.1007/S11032-011-9615-5

23. Calderón-Vázquez C, Sawers RJH, Herrera-Estrella L (2011) Phosphate deprivation in maize: Genetics and genomics. Plant Physiol 156:1067-1077. https://doi.org/10.1104/pp.111.174987

24. Carpenter SR, Bennett EM (2011) Reconsideration of the planetary boundary for phosphorus. Environ Res Lett 6:014009. https://doi.org/10.1088/1748-9326/6/1/014009

25. Castrillo G, Teixeira PJPL, Paredes SH et al (2017) Root microbiota drive direct integration of phosphate stress and immunity. Nat 20175437646 543:513-518. https://doi.org/10.1038/nature21417

26. Chen J, Xu L (2011) Comparative mapping of QTLs for H+ secretion of root in maize (Zea mays L.) and cross phosphorus levels on two growth stages. Front Agric China 2011 53 5:284-290. https://doi.org/10.1007/S11703-011-1075-5

27. Chen L, Liao H (2017) Engineering crop nutrient efficiency for sustainable agriculture. J Integr Plant Biol 59:710-735

28. Chu S, Zhang X, Yu K et al (2020) Genome-Wide Analysis Reveals Dynamic Epigenomic Differences in Soybean Response to Low-Phosphorus Stress. Int J Mol Sci 2020, Vol 21, Page 6817 21:6817. 
https://doi.org/10.3390/JJMS21186817

29. Colasuonno P, Marcotuli I, Gadaleta A, Soriano JM (2021) From genetic maps to qtl cloning: An overview for durum wheat. Plants 10:1-25

30. Cordell D, White S (2014) Life's bottleneck: Sustaining the world's phosphorus for a food secure future. Annu Rev Environ Resour 39:161-188. https://doi.org/10.1146/annurev-environ-010213113300

31. Cruz-Ramírez A, Oropeza-Aburto A, Razo-Hernández F et al (2006) Phospholipase DZ2 plays an important role in extraplastidic galactolipid biosynthesis and phosphate recycling in Arabidopsis roots. Proc Natl Acad Sci U S A 103:6765-6770. https://doi.org/10.1073/pnas.0600863103

32. Delhaize E, Rathjen TM, Cavanagh CR (2015) The genetics of rhizosheath size in a multiparent mapping population of wheat. J Exp Bot 66:4527-4536. https://doi.org/10.1093/JXB/ERV223

33. Devaiah BN, Madhuvanthi R, Karthikeyan AS, Raghothama KG (2009) Phosphate starvation responses and gibberellic acid biosynthesis are regulated by the MYB62 transcription factor in Arabidopsis. Mol Plant 2:43-58. https://doi.org/10.1093/mp/ssn081

34. Diaz LM, Ricaurte J, Cajiao C et al (2017) Phenotypic evaluation and QTL analysis of yield and symbiotic nitrogen fixation in a common bean population grown with two levels of phosphorus supply. Mol Breed 2017376 37:1-16. https://doi.org/10.1007/S11032-017-0673-1

35. Diaz RJ, Rosenberg R (2008) Spreading Dead Zones and Consequences for Marine Ecosystems. Science (80-) 321:926-929. https://doi.org/10.1126/SCIENCE.1156401

36. Dodds WK, Bouska WW, Eitzmann JL et al (2008) Eutrophication of U.S. Freshwaters: Analysis of Potential Economic Damages. Environ Sci Technol 43:12-19. https://doi.org/10.1021/ES801217Q

37. Dong J, Ma G, Sui L et al (2019) Inositol Pyrophosphate InsP8 Acts as an Intracellular Phosphate Signal in Arabidopsis. Mol Plant 12:1463-1473. https://doi.org/10.1016/j.molp.2019.08.002

38. Dong J, Piñeros MA, Li X et al (2017) An Arabidopsis ABC Transporter Mediates Phosphate Deficiency-Induced Remodeling of Root Architecture by Modulating Iron Homeostasis in Roots. Mol Plant 10:244-259. https://doi.org/10.1016/j.molp.2016.11.001

39. Du Q, Wang K, Zou C et al (2018) The PILNCR1-miR399 regulatory module is important for low phosphate tolerance in maize. Plant Physiol 177:1743-1753. https://doi.org/10.1104/pp.18.00034

40. Ehdaie B, Merhaut DJ, Ahmadian S et al (2010) Root System Size Influences Water-Nutrient Uptake and Nitrate Leaching Potential in Wheat. J Agron Crop Sci 196:455-466.

https://doi.org/10.1111/J.1439-037X.2010.00433.X

41. Esposito S, Carputo D, Cardi T, Tripodi P (2020) Applications and trends of machine learning in genomics and phenomics for next-generation breeding. Plants 9:34

42. Essigmann B, Güler S, Narang RA et al (1998) Phosphate availability affects the thylakoid lipid composition and the expression of SQD1 a gene required for sulfolipid biosynthesis in Arabidopsis thaliana. Proc Natl Acad Sci U S A 95:1950-1955. https://doi.org/10.1073/pnas.95.4.1950 
43. FAO, IFAD (2021) UNICEF W and W The State of Food Security and Nutrition in the World 2021. State Food Secur Nutr World 2021. https://doi.org/10.4060/cb4474en

44. FAO (2020) World fertilizer trends and outlook to 2022. World Fertil trends outlook to 202240. https://doi.org/10.4060/ca6746en

45. FAOSTAT (2021) FAOSTAT. In: Fertil. by Nutr. phosphate. https://www.fao.org/faostat/en/\#data. Accessed 25 Oct 2021

46. Foroozani M, Zahraeifard S, Oh D-H et al (2020) Low-Phosphate Chromatin Dynamics Predict a Cell Wall Remodeling Network in Rice Shoots. Plant Physiol 182:1494-1509. https://doi.org/10.1104/PP.19.01153

47. Franco-Zorrilla JM, Valli A, Todesco M et al (2007) Target mimicry provides a new mechanism for regulation of microRNA activity. Nat Genet 39:1033-1037. https://doi.org/10.1038/ng2079

48. Gamuyao R, Chin JH, Pariasca-Tanaka J et al (2012) The protein kinase Pstol1 from traditional rice confers tolerance of phosphorus deficiency. Nat 20124887412 488:535-539. https://doi.org/10.1038/nature11346

49. GAO S, qing CHENG, deng HUD, yi et al (2018) A major quantitative trait locus controlling phosphorus utilization efficiency under different phytate-P conditions at vegetative stage in barley. J Integr Agric 17:285-295. https://doi.org/10.1016/S2095-3119(17)61713-1

50. Gao S, Xia J, Yuan S et al (2020) Novel QTL Conferring Phosphorus Acquisition and Utilization Efficiencies in Barley. Front Genet 0:1039. https://doi.org/10.3389/FGENE.2020.580452

51. Gao W, Lu L, Qiu W et al (2017) OsPAP26 encodes a major purple acid phosphatase and regulates phosphate remobilization in rice. Plant Cell Physiol 58:885-892.

https://doi.org/10.1093/pcp/pcx041

52. Gatiboni LC, Schmitt DE, Tiecher T et al (2021) Plant uptake of legacy phosphorus from soils without P fertilization. Nutr Cycl Agroecosystems 20211191 119:139-151. https://doi.org/10.1007/S10705020-10109-2

53. Godon C, Mercier C, Wang X et al (2019) Under phosphate starvation conditions, Fe and Al trigger accumulation of the transcription factor STOP1 in the nucleus of Arabidopsis root cells. Plant $\mathrm{J}$ 99:937-949. https://doi.org/10.1111/tpj.14374

54. González-Muñoz E, Avendaño AOV, Chávez Montes RA et al (2015) The maize (Zea mays ssp. mays var. B73) genome encodes 33 members of the purple acid phosphatase family. Front Plant Sci 6:112. https://doi.org/10.3389/fpls.2015.00341

55. Gonzalez-Segovia E, Pérez-Limon S, Cíntora-Martínez GC et al (2019) Characterization of introgression from the teosinte Zea mays ssp. mexicana to Mexican highland maize. PeerJ 7:e6815. https://doi.org/10.7717/PEERJ.6815

56. Grimanelli D, Roudier F (2013) Epigenetics and Development in Plants: Green Light to Convergent Innovations. Curr Top Dev Biol 104:189-222. https://doi.org/10.1016/B978-0-12-416027-9.00006-1

57. Gu R, Chen F, Long L et al (2016a) Enhancing phosphorus uptake efficiency through QTL-based selection for root system architecture in maize. J Genet Genomics 43:663-672. 
https://doi.org/10.1016/J.JGG.2016.11.002

58. Gu Z, Eils R, Schlesner M (2016b) Complex heatmaps reveal patterns and correlations in multidimensional genomic data. Bioinformatics 32:2847-2849.

https://doi.org/10.1093/bioinformatics/btw313

59. Guo J, Chen G, Zhang X et al (2018) Quantitative trait locus analysis of adventitious and lateral root morphology of barley grown at low and high P. Funct Plant Biol 45:957-967. https://doi.org/10.1071/FP17271

60. Gutiérrez-Alanís D, Ojeda-Rivera JO, Yong-Villalobos L et al (2018) Adaptation to Phosphate Scarcity: Tips from Arabidopsis Roots. Trends Plant Sci 23:721-730.

https://doi.org/10.1016/j.tplants.2018.04.006

61. Hacisalihoglu G, Burton AL, Gustin JL et al (2018) Quantitative trait loci associated with soybean seed weight and composition under different phosphorus levels. J Integr Plant Biol 60:232-241. https://doi.org/10.1111/JIPB.12612

62. Hamburger D, Rezzonico E, Petétot JMDC et al (2002) Identification and characterization of the Arabidopsis PHO1 gene involved in phosphate loading to the xylem. Plant Cell 14:889-902. https://doi.org/10.1105/tpc.000745

63. Hasan MM, Hasan MM, Teixeira Da Silva JA, Li X (2016) Regulation of phosphorus uptake and utilization: transitioning from current knowledge to practical strategies. https://doi.org/10.1186/s11658-016-0008-y

64. Herud-Sikimić O, Stiel AC, Kolb M et al (2021) A biosensor for the direct visualization of auxin. Nat 2021 5927856 592:768-772. https://doi.org/10.1038/s41586-021-03425-2

65. Heuer S, Gaxiola R, Schilling R et al (2017) Improving phosphorus use efficiency: a complex trait with emerging opportunities. Plant J 90:868-885. https://doi.org/10.1111/tpj.13423

66. Hinsinger $P$ (2001) Bioavailability of soil inorganic $P$ in the rhizosphere as affected by root-induced chemical changes: A review. Plant and Soil. Springer, pp 173-195

67. Hiruma K, Gerlach N, Sacristán S et al (2016) Root Endophyte Colletotrichum tofieldiae Confers Plant Fitness Benefits that Are Phosphate Status Dependent. Cell 165:464-474. https://doi.org/10.1016/J.CELL.2016.02.028

68. Hoekenga OA, Maron LG, Piñeros MA et al (2006) AtALMT1, which encodes a malate transporter, is identified as one of several genes critical for aluminum tolerance in Arabidopsis. Proc Natl Acad Sci U S A 103:9738-9743. https://doi.org/10.1073/pnas.0602868103

69. Hou E, Chen C, Luo Y et al (2018) Effects of climate on soil phosphorus cycle and availability in natural terrestrial ecosystems. Glob Chang Biol 24:3344-3356. https://doi.org/10.1111/GCB.14093

70. Hou E, Luo Y, Kuang Y et al (2020) Global meta-analysis shows pervasive phosphorus limitation of aboveground plant production in natural terrestrial ecosystems. Nat Commun 2020 111 11:1-9. https://doi.org/10.1038/s41467-020-14492-w

71. Hsieh L-C, Lin S-I, Shih AC-C et al (2009) Uncovering Small RNA-Mediated Responses to Phosphate Deficiency in Arabidopsis by Deep Sequencing. Plant Physiol 151:2120-2132. 
https://doi.org/10.1104/PP.109.147280

72. Hu B, Wang W, Ou S et al (2015) Variation in NRT1.1B contributes to nitrate-use divergence between rice subspecies. Nat Genet 2015477 47:834-838. https://doi.org/10.1038/ng.3337

73. Hu B, Zhu C, Li F et al (2011) LEAF TIP NECROSIS1 Plays a Pivotal Role in the Regulation of Multiple Phosphate Starvation Responses in Rice. Plant Physiol 156:1101-1115. https://doi.org/10.1104/PP.110.170209

74. Huang TK, Han CL, Lin SI et al (2013) Identification of downstream components of ubiquitinconjugating enzyme PHOSPHATE2 by quantitative membrane proteomics in Arabidopsis roots. Plant Cell 25:4044-4060. https://doi.org/10.1105/tpc.113.115998

75. Hurley B, Tran HT, Hurley BA, Plaxton WC (2010) Feeding hungry plants: The role of purple acid phosphatases in phosphate nutrition Author's personal copy Feeding hungry plants: The role of purple acid phosphatases in phosphate nutrition. https://doi.org/10.1016/j.plantsci.2010.04.005

76. luchi S, Koyama H, luchi A et al (2007) Zinc finger protein STOP1 is critical for proton tolerance in Arabidopsis and coregulates a key gene in aluminum tolerance. Proc Natl Acad Sci U S A 104:99009905. https://doi.org/10.1073/pnas.0700117104

77. Jabnoune M, Secco D, Lecampion C et al (2013) A Rice cis-Natural Antisense RNA Acts as a Translational Enhancer for Its Cognate mRNA and Contributes to Phosphate Homeostasis and Plant Fitness. Plant Cell 25:4166-4182. https://doi.org/10.1105/TPC.113.116251

78. Jaganathan D, Ramasamy K, Sellamuthu G et al (2018) CRISPR for crop improvement: An update review. Front Plant Sci 9:985

79. James RA, Weligama C, Verbyla K et al (2016) Rhizosheaths on wheat grown in acid soils: phosphorus acquisition efficiency and genetic control. J Exp Bot 67:3709-3718. https://doi.org/10.1093/JXB/ERW035

80. Jasinski S (2021) Phosphate Rock Statistics and Information. In: USGS Natl. Miner. Inf. Cent. https://www.usgs.gov/centers/nmic/phosphate-rock-statistics-and-information. Accessed 25 Oct 2021

81. Jeong K, Baten A, Waters DLE et al (2017) Phosphorus remobilization from rice flag leaves during grain filling: an RNA-seq study. Plant Biotechnol J 15:15-26. https://doi.org/10.1111/PBI.12586

82. Jiang F, Doudna JA (2017) CRISPR-Cas9 Structures and Mechanisms. Annu Rev Biophys 46:505529

83. John DA, Babu GR (2021) Lessons From the Aftermaths of Green Revolution on Food System and Health. Front Sustain Food Syst 0:21. https://doi.org/10.3389/FSUFS.2021.644559

84. Jung WJ, Seo YW (2014) Employment of wheat-rye translocation in wheat improvement and broadening its genetic basis. J Crop Sci Biotechnol 2014 174 17:305-313. https://doi.org/10.1007/S12892-014-0086-1

85. Jyoti A, Kaushik S, Srivastava VK et al (2019) The potential application of genome editing by using CRISPR/Cas9, and its engineered and ortholog variants for studying the transcription factors 
involved in the maintenance of phosphate homeostasis in model plants. Semin Cell Dev Biol 96:7790

86. Kale RR, Rani CVD, Anila M et al (2021) Novel major QTLs associated with low soil phosphorus tolerance identified from the Indian rice landrace, Wazuhophek. PLoS ONE 16:e0254526. https://doi.org/10.1371/JOURNAL.PONE.0254526

87. Kanno S, Arrighi JF, Chiarenza S et al (2016) A novel role for the root cap in phosphate uptake and homeostasis. Elife 5. https://doi.org/10.7554/ELIFE.14577

88. Kant S, Peng M, Rothstein SJ (2011) Genetic Regulation by NLA and MicroRNA827 for Maintaining Nitrate-Dependent Phosphate Homeostasis in Arabidopsis. PLOS Genet 7:e1002021. https://doi.org/10.1371/JOURNAL.PGEN.1002021

89. Kassaw TK, Donayre-Torres AJ, Antunes MS et al (2018) Engineering synthetic regulatory circuits in plants. Plant Sci 273:13-22. https://doi.org/10.1016/j.plantsci.2018.04.005

90. Kelly AA, Froehlich JE, Dörmann P (2003) Disruption of the Two Digalactosyldiacylglycerol Synthase Genes DGD1 and DGD2 in Arabidopsis Reveals the Existence of an Additional Enzyme of Galactolipid Synthesis. Plant Cell 15:2694-2706. https://doi.org/10.1105/tpc.016675

91. Khan MS, Zaidi A, Wani PA (2007) Role of phosphate-solubilizing microorganisms in sustainable agriculture - A review. Agron Sustain Dev 2006271 27:29-43. https://doi.org/10.1051/AGRO:2006011

92. Khatodia S, Bhatotia K, Passricha N et al (2016) The CRISPR/Cas Genome-Editing Tool: Application in Improvement of Crops. Front Plant Sci 0:506. https://doi.org/10.3389/FPLS.2016.00506

93. Khosla A, Nelson DC (2016) Strigolactones, super hormones in the fight against Striga. Curr Opin Plant Biol 33:57-63. https://doi.org/10.1016/J.PBI.2016.06.001

94. Kochian LV, Hoekenga OA, Piñeros MA (2004) How do crop plants tolerate acid soils? Mechanisms of aluminum tolerance and phosphorous efficiency. Annu Rev Plant Biol 55:459-493. https://doi.org/10.1146/annurev.arplant.55.031903.141655

95. Kornberg RD, Lorch Y (2003) Chromatin Structure and Transcription. https://doi.org/101146/annurev.cb08110192003023 8:563-587. https://doi.org/10.1146/ANNUREV.CB.08.110192.003023

96. Kumawat G, Gupta S, Ratnaparkhe MB et al (2016) QTLomics in Soybean: A Way Forward for Translational Genomics and Breeding. Front Plant Sci 0:1852. https://doi.org/10.3389/FPLS.2016.01852

97. Kuo H-F, Hsu Y-Y, Lin W-C et al (2018) Arabidopsis inositol phosphate kinases IPK1 and ITPK1 constitute a metabolic pathway in maintaining phosphate homeostasis. Plant J 95:613-630. https://doi.org/10.1111/TPJ.13974

98. Lambers H, Cawthray GR, Giavalisco P et al (2012) Proteaceae from severely phosphorusimpoverished soils extensively replace phospholipids with galactolipids and sulfolipids during leaf development to achieve a high photosynthetic phosphorus-use-efficiency. New Phytol 196:10981108. https://doi.org/10.1111/j.1469-8137.2012.04285.x 
99. Lambers H, Finnegan PM, Laliberté E et al (2011) Phosphorus Nutrition of Proteaceae in Severely Phosphorus-Impoverished Soils: Are There Lessons To Be Learned for Future Crops? Plant Physiol 156:1058-1066. https://doi.org/10.1104/PP.111.174318

100. Land ES, Cridland CA, Craige B et al (2021) A Role for Inositol Pyrophosphates in the Metabolic Adaptations to Low Phosphate in Arabidopsis. Metab 2021, Vol 11, Page 601 11:601. https://doi.org/10.3390/METAB011090601

101. Lee HY, Chen Z, Zhang C, Yoon GM (2019) Editing of the OsACS locus alters phosphate deficiencyinduced adaptive responses in rice seedlings. J Exp Bot 70:1927-1940. https://doi.org/10.1093/jxb/erz074

102. Lew TTS, Koman VB, Silmore KS et al (2020) Real-time detection of wound-induced H2O2 signalling waves in plants with optical nanosensors. Nat Plants 202064 6:404-415. https://doi.org/10.1038/s41477-020-0632-4

103. Lew TTS, Park M, Cui J, Strano MS (2021) Plant Nanobionic Sensors for Arsenic Detection. Adv Mater 33:2005683. https://doi.org/10.1002/ADMA.202005683

104. Li C, Gui S, Yang T et al (2012) Identification of soybean purple acid phosphatase genes and their expression responses to phosphorus availability and symbiosis. Ann Bot 109:275-285. https://doi.org/10.1093/aob/mcr246

105. Li D, Zhu H, Liu K et al (2002) Purple Acid Phosphatases of Arabidopsis thaliana COMPARATIVE ANALYSIS AND DIFFERENTIAL REGULATION. https://doi.org/10.1074/jbc.M204183200. BY PHOSPHATE DEPRIVATION*

106. Li J, Zhang X, Sun Y et al (2018) Efficient allelic replacement in rice by gene editing: A case study of the NRT1.1B gene. J. Integr. Plant Biol 60:536-540

107. Liang Z, Zhang K, Chen K, Gao C (2014) Targeted mutagenesis in Zea mays using TALENs and the CRISPR/Cas system. J Genet Genomics 41:63-68. https://doi.org/10.1016/j.jgg.2013.12.001

108. Lin W-Y, Huang T-K, Chiou T-J (2013) NITROGEN LIMITATION ADAPTATION, a Target of MicroRNA827, Mediates Degradation of Plasma Membrane-Localized Phosphate Transporters to Maintain Phosphate Homeostasis in Arabidopsis. Plant Cell 25:4061-4074. https://doi.org/10.1105/TPC.113.116012

109. Lindemose S, O'Shea C, Jensen MK, Skriver K (2013) Structure, function and networks of transcription factors involved in abiotic stress responses. Int J Mol Sci 14:5842-5878

110. Liu F, Xu Y, Han G et al (2018a) Identification and functional characterization of a maize phosphate transporter induced by mycorrhiza formation. Plant Cell Physiol 59:1683-1694. https://doi.org/10.1093/pcp/pcy094

111. Liu H, Yang H, Wu C et al (2009) Overexpressing HRS1 confers hypersensitivity to low phosphateelicited inhibition of primary root growth in Arabidopsis thaliana. J Integr Plant Biol 51:382-392. https://doi.org/10.1111/j.1744-7909.2009.00819.x

112. Liu N, Shang W, Li C et al (2018b) Evolution of the SPX gene family in plants and its role in the response mechanism to phosphorus stress.Open Biol.8 
113. Liu TY, Huang TK, Tseng CY et al (2012) PHO2-dependent degradation of PHO1 modulates phosphate homeostasis in Arabidopsis. Plant Cell 24:2168-2183.

https://doi.org/10.1105/tpc.112.096636

114. Liu W, Stewart CN (2015) Plant synthetic biology. Trends Plant Sci 20:309-317

115. López-Arredondo DL, Herrera-Estrella L (2012) Engineering phosphorus metabolism in plants to produce a dual fertilization and weed control system. Nat Biotechnol 30:889-893. https://doi.org/10.1038/nbt.2346

116. López-Arredondo DL, Leyva-González MA, González-Morales SI et al (2014) Phosphate Nutrition: Improving Low-Phosphate Tolerance in Crops. Annu Rev Plant Biol 65:95-123. https://doi.org/10.1146/annurev-arplant-050213-035949

117. López-Bucio J, Hernández-Abreu E, Sánchez-Calderón L et al (2002) Phosphate availability alters architecture and causes changes in hormone sensitivity in the Arabidopsis root system. Plant Physiol 129:244-256. https://doi.org/10.1104/pp.010934

118. Lu Y, Zhu JK (2017) Precise Editing of a Target Base in the Rice Genome Using a Modified CRISPR/Cas9 System. Mol Plant 10:523-525. https://doi.org/10.1016/J.MOLP.2016.11.013

119. Lucas FLR, Versloot RCA, Yakovlieva $L$ et al (2021) Protein identification by nanopore peptide profiling. Nat Commun 12:1-9. https://doi.org/10.1038/s41467-021-26046-9

120. Lynch JP, Brown KM (2001) Topsoil foraging - An architectural adaptation of plants to low phosphorus availability. Plant and Soil. Springer, pp 225-237

121. Mackey KRM, Paytan A (2009) Phosphorus Cycle. Encyclopedia of Microbiology. Academic Press, pp 322-334

122. Maharajan T, Ceasar SA, krishna TPA et al (2018) Utilization of molecular markers for improving the phosphorus efficiency in crop plants. Plant Breed 137:10-26. https://doi.org/10.1111/PBR.12537

123. Mahender A, Anandan A, Pradhan SK, Singh ON (2018) Traits-related QTLs and genes and their potential applications in rice improvement under low phosphorus condition. Arch Agron Soil Sci 64:449-464

124. Mai NTP, Mai CD, Nguyen $H$, Van et al (2021) Discovery of new genetic determinants of morphological plasticity in rice roots and shoots under phosphate starvation using GWAS. J Plant Physiol 257:153340. https://doi.org/10.1016/J.JPLPH.2020.153340

125. Malhotra H, Vandana, Sharma S, Pandey R (2018) Phosphorus Nutrition: Plant Growth in Response to Deficiency and Excess. Plant Nutr Abiotic Stress Toler 171-190. https://doi.org/10.1007/978-98110-9044-8_7

126. Manna M, Achary VMM, Islam T et al (2016) The development of a phosphite-mediated fertilization and weed control system for rice. Sci Rep 6:1-12. https://doi.org/10.1038/srep24941

127. Marathe A, Krishnan V, Vinutha T et al (2018) Exploring the role of Inositol 1,3,4-trisphosphate $5 / 6$ kinase-2 (GmITPK2) as a dehydration and salinity stress regulator in Glycine max (L.) Merr. through heterologous expression in E. coli. Plant Physiol Biochem 123:331-341. https://doi.org/10.1016/j.plaphy.2017.12.026

Page $37 / 52$ 
128. Mayzlish-Gati E, De-Cuyper C, Goormachtig S et al (2012) Strigolactones are involved in root response to low phosphate conditions in arabidopsis. Plant Physiol 160:1329-1341. https://doi.org/10.1104/pp.112.202358

129. Medford JI, Prasad A (2014) Plant synthetic biology takes root. Science (80-) 346:162-163. https://doi.org/10.1126/SCIENCE.1261140

130. Medici A, Marshall-Colon A, Ronzier E et al (2015) AtNIGT1/HRS1 integrates nitrate and phosphate signals at the Arabidopsis root tip. Nat Commun 6:1-11. https://doi.org/10.1038/ncomms7274

131. Mellor J (2005) The Dynamics of Chromatin Remodeling at Promoters. Mol Cell 19:147-157. https://doi.org/10.1016/J.MOLCEL.2005.06.023

132. Milner MJ, Howells RM, Craze M et al (2018) A PSTOL-like gene, TaPSTOL, controls a number of agronomically important traits in wheat. BMC Plant Biol 18. https://doi.org/10.1186/S12870-018$1331-4$

133. Mogollón JM, Bouwman AF, Beusen AHW et al (2021) More efficient phosphorus use can avoid cropland expansion. Nat Food 202127 2:509-518. https://doi.org/10.1038/s43016-021-00303-y

134. Montecillo JAV, Chu LL, Bae H (2020) CRISPR-Cas9 System for Plant Genome Editing: Current Approaches and Emerging Developments. Agron 2020, Vol 10, Page 1033 10:1033. https://doi.org/10.3390/AGRONOMY10071033

135. Mora-Macías J, Ojeda-Rivera JO, Gutiérrez-Alanís D et al (2017) Malate-dependent Fe accumulation is a critical checkpoint in the root developmental response to low phosphate. Proc Natl Acad Sci U S A 114:E3563-E3572. https://doi.org/10.1073/pnas.1701952114

136. Moskal K, Kowalik S, Podyma W et al (2021) The Pros and Cons of Rye Chromatin Introgression into Wheat Genome. Agron 2021, Vol 11, Page 456 11:456.

https://doi.org/10.3390/AGRONOMY11030456

137. Nahampun HN, López-Arredondo D, Xu X et al (2016) Assessment of ptxD gene as an alternative selectable marker for Agrobacterium-mediated maize transformation. Plant Cell Reports 2016355 35:1121-1132. https://doi.org/10.1007/S00299-016-1942-X

138. Niu X, Chen Q, Wang X (2008) OsITL1 gene encoding an inositol 1,3,4-trisphosphate 5/6-kinase is a negative regulator of osmotic stress signaling. Biotechnol Lett 30:1687-1692. https://doi.org/10.1007/s10529-008-9730-5

139. Nussaume L, Kanno S, Javot $\mathrm{H}$ et al (2011) Phosphate Import in Plants: Focus on the PHT1 Transporters. Front Plant Sci 0:83. https://doi.org/10.3389/FPLS.2011.00083

140. O'Malley RC, Huang SSC, Song L et al (2016) Cistrome and Epicistrome Features Shape the Regulatory DNA Landscape. Cell 165:1280-1292. https://doi.org/10.1016/j.cell.2016.04.038

141. Ochoa IE, Blair MW, Lynch JP (2006) QTL Analysis of Adventitious Root Formation in Common Bean under Contrasting Phosphorus Availability. Crop Sci 46:1609-1621.

https://doi.org/10.2135/CROPSCI2005.12-0446

142. Ojeda-Rivera JO, Oropeza-Aburto A, Herrera-Estrella L (2020) Dissection of Root Transcriptional Responses to Low pH, Aluminum Toxicity and Iron Excess Under Pi-Limiting Conditions in 
Arabidopsis Wild-Type and stop1 Seedlings. Front Plant Sci 11:1200.

https://doi.org/10.3389/fpls.2020.01200

143. Okazaki Y, Otsuki H, Narisawa T et al (2013) A new class of plant lipid is essential for protection against phosphorus depletion. Nat Commun 201341 4:1-10. https://doi.org/10.1038/ncomms2512

144. Pandey GK (2020) Protein Phosphatases and Stress Management in Plants

145. Pandeya D, López-Arredondo DL, Janga MR et al (2018) Selective fertilization with phosphite allows unhindered growth of cotton plants expressing the ptxD gene while suppressing weeds. Proc Natl Acad Sci 115:E6946-E6955. https://doi.org/10.1073/PNAS.1804862115

146. Patikoglou G, Burley SK (1997) Eukaryotic transcription factor-DNA complexes. Annu Rev Biophys Biomol Struct 26:289-325

147. Pavinato PS, Cherubin MR, Soltangheisi A et al (2020) Revealing soil legacy phosphorus to promote sustainable agriculture in Brazil. Sci Reports 2020101 10:1-11. https://doi.org/10.1038/s41598020-72302-1

148. Peng Y, Hu Y, Qian Q, Ren D (2021) Progress and Prospect of Breeding Utilization of Green Revolution Gene SD1 in Rice. Agric 2021, Vol 11, Page 611 11:611.

https://doi.org/10.3390/AGRICULTURE11070611

149. Perera I, Seneweera S, Hirotsu N (2018) Manipulating the Phytic Acid Content of Rice Grain Toward Improving Micronutrient Bioavailability. https://doi.org/10.1186/S12284-018-0200-Y. Rice 11:

150. Péret B, Clément M, Nussaume L, Desnos T (2011) Root developmental adaptation to phosphate starvation: Better safe than sorry. Trends Plant Sci 16:442-450

151. Pérez-Torres C-A, López-Bucio J, Cruz-Ramírez A et al (2008) Phosphate Availability Alters Lateral Root Development in Arabidopsis by Modulating Auxin Sensitivity via a Mechanism Involving the TIR1 Auxin Receptor. Plant Cell 20:3258. https://doi.org/10.1105/TPC.108.058719

152. Pingali PL (2012) Green Revolution: Impacts, limits, and the path ahead. Proc Natl Acad Sci 109:12302-12308. https://doi.org/10.1073/PNAS.0912953109

153. Plaxton WC, Tran HT (2011) Metabolic adaptations of phosphate-starved plants. Plant Physiol 156:1006-1015. https://doi.org/10.1104/pp.111.175281

154. Poirier Y, Thoma S, Somerville C, Schiefelbein J (1991) A mutant of Arabidopsis deficient in xylem loading of phosphate. Plant Physiol 97:1087-1093. https://doi.org/10.1104/pp.97.3.1087

155. Pouvreau B, Vanhercke T, Singh S (2018) From plant metabolic engineering to plant synthetic biology: The evolution of the design/build/test/learn cycle. Plant Sci 273:3-12. https://doi.org/10.1016/J.PLANTSCI.2018.03.035

156. Puga MI, Mateos I, Charukesi R et al (2014) SPX1 is a phosphate-dependent inhibitor of Phosphate Starvation Response 1 in Arabidopsis. Proc Natl Acad Sci U S A 111:14947-14952. https://doi.org/10.1073/pnas.1404654111

157. Qiu H, Liu C, Yu T et al (2014) Identification of QTL for acid phosphatase activity in root and rhizosphere soil of maize under low phosphorus stress. Euphytica 20141971 197:133-143. 
https://doi.org/10.1007/S10681-013-1058-0

158. Raboy V (2001) Seeds for a better future: "Low phytate" grains help to overcome malnutrition and reduce pollution. Trends Plant Sci 6:458-462

159. Raghothama KG (1999) Phosphate acquisition. Annu Rev Plant Biol 50:665-693. https://doi.org/10.1146/annurev.arplant.50.1.665

160. Raghothama KG, Karthikeyan AS (2005) Phosphate acquisition. Plant Soil 274:37-49. https://doi.org/10.1007/s11104-004-2005-6

161. Ramírez-Flores MR, Perez-Limon S, Li M et al (2020) The genetic architecture of host response reveals the importance of arbuscular mycorrhizae to maize cultivation. Elife 9:1-18. https://doi.org/10.7554/ELIFE.61701

162. Ranganathan J, Waite R, Searchinger T, Hanson C (2018) How to Sustainably Feed 10 Billion People by 2050 , in 21 Charts

163. Ray DK, Foley JA (2013) Increasing global crop harvest frequency: recent trends and future directions. Environ Res Lett 8:044041. https://doi.org/10.1088/1748-9326/8/4/044041

164. Raya-González J, Ojeda-Rivera JO, Mora-Macias J et al (2021) MEDIATOR16 orchestrates local and systemic responses to phosphate scarcity in Arabidopsis roots. New Phytol 229:1278-1288. https://doi.org/10.1111/NPH.16989

165. Rellán-Álvarez R, Lobet G, Lindner H et al (2015) GLO-Roots: An imaging platform enabling multidimensional characterization of soil-grown root systems. Elife 4. https://doi.org/10.7554/eLife.07597

166. Ren Y, Qian Y, Xu Y et al (2017) Characterization of QTLs for Root Traits of Wheat Grown under Different Nitrogen and Phosphorus Supply Levels. Front Plant Sci 0:2096. https://doi.org/10.3389/FPLS.2017.02096

167. Ried MK, Wild R, Zhu J et al (2021) Inositol pyrophosphates promote the interaction of SPX domains with the coiled-coil motif of PHR transcription factors to regulate plant phosphate homeostasis. Nat Commun 2021121 12:1-13. https://doi.org/10.1038/s41467-020-20681-4

168. Rockström J, Steffen W, Noone K et al (2009) Planetary boundaries: Exploring the safe operating space for humanity. Ecol Soc 14. https://doi.org/10.5751/ES-03180-140232

169. Rubio V, Linhares F, Solano R et al (2001) A conserved MYB transcription factor involved in phosphate starvation signaling both in vascular plants and in unicellular algae. Genes Dev 15:21222133. https://doi.org/10.1101/gad.204401

170. Ryan PR, Liao M, Delhaize E et al (2015) Early vigour improves phosphate uptake in wheat. J Exp Bot 66:7089-7100. https://doi.org/10.1093/JXB/ERV403

171. Salas-González I, Reyt G, Flis P et al (2021) Coordination between microbiota and root endodermis supports plant mineral nutrient homeostasis. Science (80-) 371:.

https://doi.org/10.1126/SCIENCE.ABD0695 
172. Salazar-Vidal MN, Acosta-Segovia E, Sánchez-León N et al (2016) Characterization and Transposon Mutagenesis of the Maize (Zea mays) Pho1 Gene Family. PLoS ONE 11:e0161882. https://doi.org/10.1371/journal.pone.0161882

173. Sánchez-Calderón L, López-Bucio J, Chacón-López A et al (2005) Phosphate Starvation Induces a Determinate Developmental Program in the Roots of Arabidopsis thaliana. Plant Cell Physiol 46:174-184. https://doi.org/10.1093/pcp/pci011

174. Santoro V, Schiavon M, Gresta F et al (2020) Strigolactones control root system architecture and tip anatomy in solanum lycopersicum I. Plants under $p$ starvation. Plants 9:612. https://doi.org/10.3390/plants9050612

175. Sattari SZ, Bouwman AF, Giller KE, van Ittersum MK (2012) Residual soil phosphorus as the missing piece in the global phosphorus crisis puzzle. Proc Natl Acad Sci 109:6348-6353. https://doi.org/10.1073/PNAS.1113675109

176. Savage N, Yang TJW, Chen CY et al (2013) Positional Signaling and Expression of ENHANCER OF TRY AND CPC1 Are Tuned to Increase Root Hair Density in Response to Phosphate Deficiency in Arabidopsis thaliana. PLoS ONE 8:e75452. https://doi.org/10.1371/journal.pone.0075452

177. Sawaki Y, luchi S, Kobayashi Y et al (2009) Stop1 regulates multiple genes that protect arabidopsis from proton and aluminum toxicities. Plant Physiol 150:281-294.

https://doi.org/10.1104/pp.108.134700

178. Schachtman DP, Reid RJ, Ayling SM (1998) Phosphorus Uptake by Plants: From Soil to Cell. Plant Physiol 116:447-453. https://doi.org/10.1104/PP.116.2.447

179. Secco D, Baumann A, Poirier Y (2010) Characterization of the rice PHO1 gene family reveals a key role for OsPH01;2 in phosphate homeostasis and the evolution of a distinct clade in dicotyledons. Plant Physiol 152:1693-1704. https://doi.org/10.1104/pp.109.149872

180. Secco D, Wang C, Shou $\mathrm{H}$ et al (2015) Stress induced gene expression drives transient DNA methylation changes at adjacent repetitive elements. Elife 4. https://doi.org/10.7554/ELIFE.09343

181. Séré D, Martin A (2019) Epigenetic regulation: another layer in plant nutrition. https://doi.org/101080/1559232420191686236 15:. https://doi.org/10.1080/15592324.2019.1686236

182. Sharpley A, Jarvie HP, Buda A et al (2013) Phosphorus Legacy: Overcoming the Effects of Past Management Practices to Mitigate Future Water Quality Impairment. J Environ Qual 42:1308-1326. https://doi.org/10.2134/jeq2013.03.0098

183. Sheard LB, Tan X, Mao H et al (2010) Jasmonate perception by inositol-phosphate-potentiated COI1JAZ co-receptor. Nature 468:400-407. https://doi.org/10.1038/nature09430

184. Shi J, Wang H, Wu Y et al (2003) The Maize Low-Phytic Acid Mutant Ipa2 Is Caused by Mutation in an Inositol Phosphate Kinase Gene. Plant Physiol 131:507-515. https://doi.org/10.1104/PP.014258

185. Shi J, Zhao B, Zheng S et al (2021) A phosphate starvation response-centered network regulates mycorrhizal symbiosis. Cell. https://doi.org/10.1016/J.CELL.2021.09.030 
186. Shin H, Shin HS, Dewbre GR, Harrison MJ (2004) Phosphate transport in Arabidopsis: Pht1;1 and Pht1;4 play a major role in phosphate acquisition from both low- and high-phosphate environments. Plant J 39:629-642. https://doi.org/10.1111/j.1365-313X.2004.02161.x

187. Shukla VK, Doyon Y, Miller JC et al (2009) Precise genome modification in the crop species Zea mays using zinc-finger nucleases. Nat 20094597245 459:437-441. https://doi.org/10.1038/nature07992

188. Smith SE, Jakobsen I, Grønlund M, Smith FA (2011) Roles of Arbuscular Mycorrhizas in Plant Phosphorus Nutrition: Interactions between Pathways of Phosphorus Uptake in Arbuscular Mycorrhizal Roots Have Important Implications for Understanding and Manipulating Plant Phosphorus Acquisition. Plant Physiol 156:1050-1057. https://doi.org/10.1104/PP.111.174581

189. Sun H, Tao J, Liu S et al (2014) Strigolactones are involved in phosphate- and nitrate-deficiencyinduced root development and auxin transport in rice. J Exp Bot 65:6735-6746. https://doi.org/10.1093/jxb/eru029

190. Swamy HKM, Anila M, Kale RR et al (2019) Phenotypic and molecular characterization of rice germplasm lines and identification of novel source for low soil phosphorus tolerance in rice. Euphytica 20192157 215:1-15. https://doi.org/10.1007/S10681-019-2443-0

191. Tamura Y, Kobae Y, Mizuno T, Hata S (2012) Identification and expression analysis of arbuscular mycorrhiza-inducible phosphate transporter genes of soybean. Biosci Biotechnol Biochem 76:309313. https://doi.org/10.1271/bbb.110684

192. Tan X, Calderon-Villalobos LIA, Sharon M et al (2007) Mechanism of auxin perception by the TIR1 ubiquitin ligase. Nat 20074467136 446:640-645. https://doi.org/10.1038/nature05731

193. The World Bank (2021) Commodity Markets. https://www.worldbank.org/en/research/commoditymarkets. Accessed 25 Oct 2021

194. Thibaud MC, Arrighi JF, Bayle V et al (2010) Dissection of local and systemic transcriptional responses to phosphate starvation in Arabidopsis. Plant J 64:775-789. https://doi.org/10.1111/j.1365-313X.2010.04375.x

195. Tian P, Lin Z, Lin D et al (2021) The pattern of DNA methylation alteration, and its association with the changes of gene expression and alternative splicing during phosphate starvation in tomato. Plant J. https://doi.org/10.1111/TPJ.15486

196. Tiessen H (2008) Phosphorus in the global environment. 1-7. https://doi.org/10.1007/978-1-40208435-5_1

197. Tilman D, Balzer C, Hill J, Befort BL (2011) Global food demand and the sustainable intensification of agriculture. 108:20260-20264. https://doi.org/10.1073/pnas.1116437108

198. To HTM, Le KQ, Van Nguyen $\mathrm{H}$ et al (2020) A genome-wide association study reveals the quantitative trait locus and candidate genes that regulate phosphate efficiency in a Vietnamese rice collection. Physiol Mol Biol Plants 20202611 26:2267-2281. https://doi.org/10.1007/S12298-020-00902-2

199. Tran HT, Qian W, Hurley BA et al (2010) Biochemical and molecular characterization of AtPAP12 and AtPAP26: the predominant purple acid phosphatase isozymes secreted by phosphate-starved. https://doi.org/10.1111/j.1365-3040.2010.02184.x 
200. UN Department of Economics and Social Affairs (2015) World Population Prospects - Population Division - United Nations. In: Int. J. Logist. Manag. https://population.un.org/wpp/. Accessed 25 Oct 2021

201. Valdés-López O, Arenas-Huertero C, Ramírez M et al (2008) Essential role of MYB transcription factor: PvPHR1 and microRNA: PvmiR399 in phosphorus-deficiency signalling in common bean roots. Plant, Cell Environ 31:1834-1843. https://doi.org/10.1111/j.1365-3040.2008.01883.x

202. Valeeva LR, Nyamsuren C, Sharipova MR, Shakirov EV (2018) Heterologous Expression of Secreted Bacterial BPP and HAP Phytases in Plants Stimulates Arabidopsis thaliana Growth on Phytate. Front Plant Sci 0:186. https://doi.org/10.3389/FPLS.2018.00186

203. Versaw WK, Garcia LR (2017) Intracellular transport and compartmentation of phosphate in plants. Curr Opin Plant Biol 39:25-30. https://doi.org/10.1016/J.PBI.2017.04.015

204. Vlčko T, Ohnoutková L (2020) Allelic variants of CRISPR/Cas9 induced mutation in an inositol trisphosphate 5/6 kinase gene manifest different phenotypes in Barley. Plants 9. https://doi.org/10.3390/plants9020195

205. Wang D, Lv S, Jiang P, Li Y (2017) Roles, regulation, and agricultural application of plant phosphate transporters.Front. Plant Sci.8

206. Wang H, Wei J, Li P et al (2019a) Integrating GWAS and gene expression analysis identifies candidate genes for root morphology traits in Maize at the seedling stage. Genes (Basel) 10:773. https://doi.org/10.3390/genes10100773

207. Wang J, Sun J, Miao J et al (2013) A phosphate starvation response regulator Ta-PHR1 is involved in phosphate signalling and increases grain yield in wheat. Ann Bot 111:1139-1153. https://doi.org/10.1093/AOB/MCT080

208. Wang L, Li Z, Qian W et al (2011) The arabidopsis purple acid phosphatase AtPAP10 is predominantly associated with the root surface and plays an important role in plant tolerance to phosphate limitation. Plant Physiol 157:1283-1299. https://doi.org/10.1104/pp.111.183723

209. Wang T, Zhang H, Zhu H (2019b) CRISPR technology is revolutionizing the improvement of tomato and other fruit crops. Hortic Res 201961 6:1-13. https://doi.org/10.1038/s41438-019-0159-x

210. Wang W, Ding G-D, White PJ et al (2018) Mapping and cloning of quantitative trait loci for phosphorus efficiency in crops: opportunities and challenges. Plant Soil 20184391 439:91-112. https://doi.org/10.1007/S11104-018-3706-6

211. Wang Y, Gao H, He L et al (2019c) The PHOSPHATE1 genes participate in salt and Pi signaling pathways and play adaptive roles during soybean evolution. BMC Plant Biol 2019 191 19:1-19. https://doi.org/10.1186/S12870-019-1959-8

212. Wang Z, Ruan W, Shi J et al (2014) Rice SPX1 and SPX2 inhibit phosphate starvation responses through interacting with PHR2 in a phosphate-dependent manner. Proc Natl Acad Sci U S A 111:14953-14958. https://doi.org/10.1073/pnas.1404680111

213. Wege S, Khan GA, Jung J-Y et al (2016) The EXS Domain of PHO1 Participates in the Response of Shoots to Phosphate Deficiency via a Root-to-Shoot Signal. Plant Physiol 170:385. 
https://doi.org/10.1104/PP.15.00975

214. Wild R, Gerasimaite R, Jung JY et al (2016) Control of eukaryotic phosphate homeostasis by inositol polyphosphate sensor domains. Science (80-) 352:986-990.

https://doi.org/10.1126/science.aad9858

215. Willmann M, Gerlach N, Buer B et al (2013) Mycorrhizal phosphate uptake pathway in maize: vital for growth and cob development on nutrient poor agricultural and greenhouse soils. Front Plant Sci 0:533. https://doi.org/10.3389/FPLS.2013.00533

216. Wissuwa M, Wegner J, Ae N, Yano M (2002) Substitution mapping of Pup1: A major QTL increasing phosphorus uptake of rice from a phosphorus-deficient soil. Theor Appl Genet 105:890-897. https://doi.org/10.1007/s00122-002-1051-9

217. Wong MH, Giraldo JP, Kwak SY et al (2017) Nitroaromatic detection and infrared communication from wild-type plants using plant nanobionics. Nat Mater 16:264-272. https://doi.org/10.1038/nmat4771

218. Wu D, Li C, Jing Y et al (2020) Identification of quantitative trait loci underlying soybean (Glycine max) 100-seed weight under different levels of phosphorus fertilizer application. Plant Breed 139:959-968. https://doi.org/10.1111/PBR.12850

219. Xu F, Liu Q, Chen L et al (2013) Genome-wide identification of soybean microRNAs and their targets reveals their organ-specificity and responses to phosphate starvation. BMC Genomics 14:66. https://doi.org/10.1186/1471-2164-14-66

220. Xu JM, Wang ZQ, Wang JY et al (2020) Low phosphate represses histone deacetylase complex1 to regulate root system architecture remodeling in Arabidopsis. New Phytol 225:1732-1745. https://doi.org/10.1111/NPH.16264

221. Xu Y, Wang R, Tong Y et al (2014) Mapping QTLs for yield and nitrogen-related traits in wheat: influence of nitrogen and phosphorus fertilization on QTL expression. Theor Appl Genet 127:59-72. https://doi.org/10.1007/s00122-013-2201-y

222. Yacoubou A-M, Wallis NZ, Menkir A et al (2021) Breeding maize (Zea mays) for Striga resistance: Past, current and prospects in sub-saharan africa. Plant Breed 140:195-210. https://doi.org/10.1111/PBR.12896

223. Yamaji N, Takemoto Y, Miyaji T et al (2017) Reducing phosphorus accumulation in rice grains with an impaired transporter in the node. Nature 541:92-95. https://doi.org/10.1038/nature20610

224. Yang M, Wang C, Hassan MA et al (2021) QTL mapping of root traits in wheat under different phosphorus levels using hydroponic culture. BMC Genomics 2021221 22:1-12. https://doi.org/10.1186/S12864-021-07425-4

225. Yang S-Y, Grønlund M, Jakobsen I et al (2012) Nonredundant Regulation of Rice Arbuscular Mycorrhizal Symbiosis by Two Members of the PHOSPHATE TRANSPORTER1 Gene Family. Plant Cell 24:4236-4251. https://doi.org/10.1105/TPC.112.104901

226. Ye Y, Yuan J, Chang X et al (2015) The Phosphate Transporter Gene OsPht1;4 Is Involved in Phosphate Homeostasis in Rice. https://doi.org/10.1371/journal.pone.0126186 
227. Yong-Villalobos L, González-Morales SI, Wrobel K et al (2015) Methylome analysis reveals an important role for epigenetic changes in the regulation of the Arabidopsis response to phosphate starvation. Proc Natl Acad Sci 112:E7293-E7302. https://doi.org/10.1073/PNAS.1522301112

228. Yu X, Keitel C, Dijkstra FA (2021) Global analysis of phosphorus fertilizer use efficiency in cereal crops. Glob Food Sec 29:100545. https://doi.org/10.1016/J.GFS.2021.100545

229. Yuan Y, Gao M, Zhang M et al (2017) QTL Mapping for Phosphorus Efficiency and Morphological Traits at Seedling and Maturity Stages in Wheat. Front Plant Sci 0:614. https://doi.org/10.3389/FPLS.2017.00614

230. Yue W, Ying Y, Wang C et al (2017) OsNLA1, a RING-type ubiquitin ligase, maintains phosphate homeostasis in Oryza sativa via degradation of phosphate transporters. Plant J 90:1040-1051. https://doi.org/10.1111/TPJ.13516

231. Zhang D, Li H, Wang J et al (2016) High-Density Genetic Mapping Identifies New Major Loci for Tolerance to Low-Phosphorus Stress in Soybean. Front Plant Sci 0:372. https://doi.org/10.3389/FPLS.2016.00372

232. Zhang H, Lang Z, Zhu J-K (2018a) Dynamics and function of DNA methylation in plants. Nat Rev Mol Cell Biol 2018198 19:489-506. https://doi.org/10.1038/s41580-018-0016-z

233. Zhang H, Wang H (2014) QTL mapping for traits related to P-deficient tolerance using three related RIL populations in wheat. Euphytica 20142033 203:505-520. https://doi.org/10.1007/S10681-0141248-4

234. Zhang Q, Wang C, Tian J et al (2011) Identification of rice purple acid phosphatases related to posphate starvation signalling. Plant Biol 13:7-15. https://doi.org/10.1111/j.14388677.2010.00346.x

235. Zhang Y, Anis GB, Wang R et al (2018b) Genetic dissection of QTL against phosphate deficiency in the hybrid rice 'Xieyou9308'. Plant Growth Regul 2017841 84:123-133. https://doi.org/10.1007/S10725-017-0326-8

236. Zhao P, You Q, Lei M (2019) A CRISPR/Cas9 deletion into the phosphate transporter SIPH01;1 reveals its role in phosphate nutrition of tomato seedlings. Physiol Plant 167:556-563. https://doi.org/10.1111/ppl.12897

237. Zhou J, Jiao F, Wu Z et al (2008) OsPHR2 Is Involved in Phosphate-Starvation Signaling and Excessive Phosphate Accumulation in Shoots of Plants. Plant Physiol 146:1673-1686. https://doi.org/10.1104/PP.107.111443

238. Zhou Z, Wang Z, Lv Q et al (2015) SPX proteins regulate Pi homeostasis and signaling in different subcellular level. Plant Signal Behav 10. https://doi.org/10.1080/15592324.2015.1061163

239. Zhu J, Lau K, Puschmann R et al (2019) Two bifunctional inositol pyrophosphate kinases/phosphatases control plant phosphate homeostasis. Elife 8. https://doi.org/10.7554/eLife.43582

240. Zogli P, Pingault L, Libault M (2017) Physiological and molecular mechanisms and adaptation strategies in soybean (Glycine max) under phosphate deficiency. Legume Nitrogen Fixation in Soils 
with Low Phosphorus Availability: Adaptation and Regulatory Implication. Springer, Cham, pp 219-

\section{Figures}

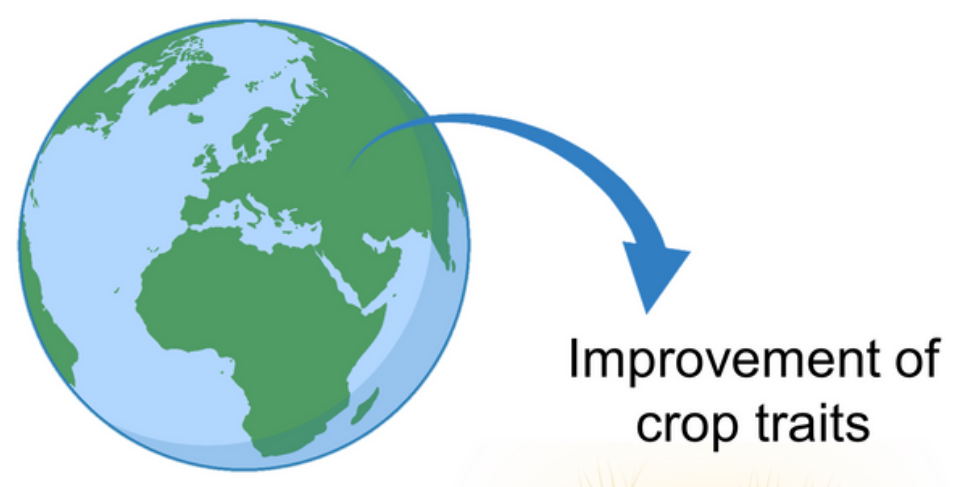

Better-designed agricultural practices

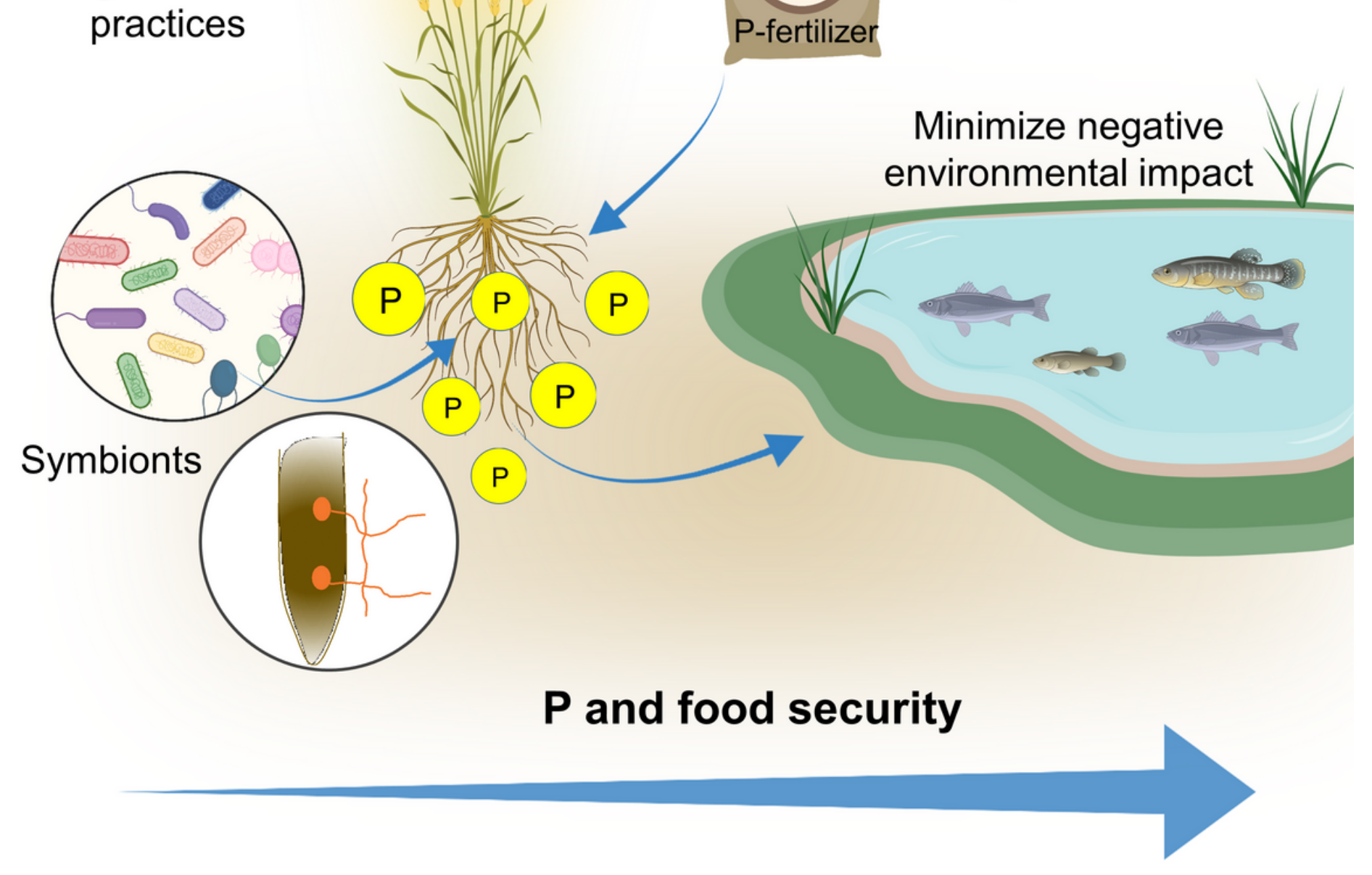

Figure 1 
Paths towards phosphorus $(P)$ and food security. Science-driven strategies should be implemented to be able to produce enough food to feed the growing population for the coming years. These strategies include for instance: substantial improvement of agricultural practices (i.e. fertile land and water use), development and improvement of technologies for $\mathrm{P}$ recycling from agricultural and industrial wastewater, deployment of symbionts, and improvement of crops traits. Improvement of plant P uptake and utilization plays a crucial role towards $\mathrm{P}$ and food security. Some elements in this figure were designed using BioRender.

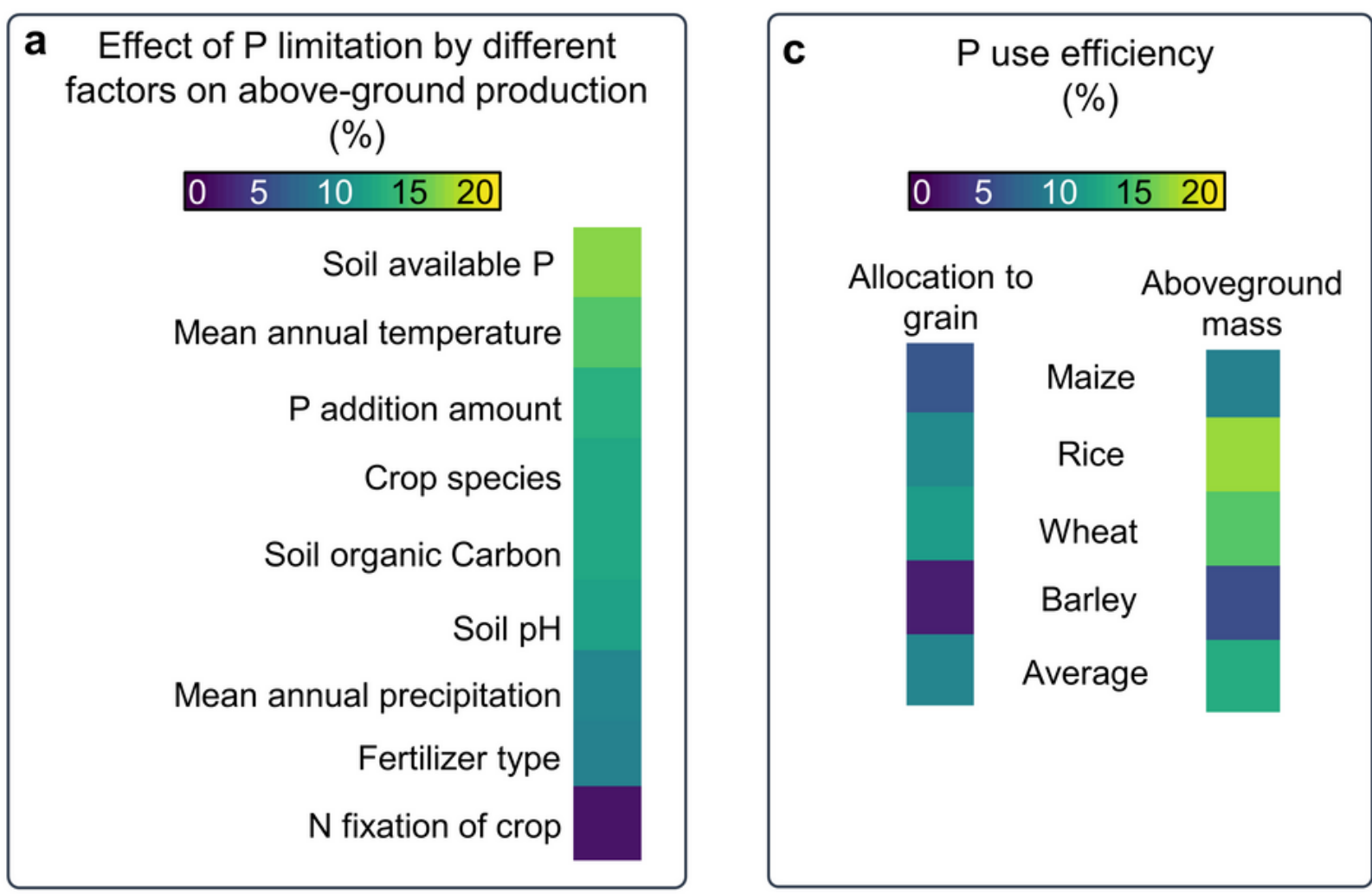

b P fertilization effect on the increase of above-ground plant production (\%)

\begin{tabular}{lllll|}
0 & 10 & 20 & 30 & 40 \\
\hline
\end{tabular}

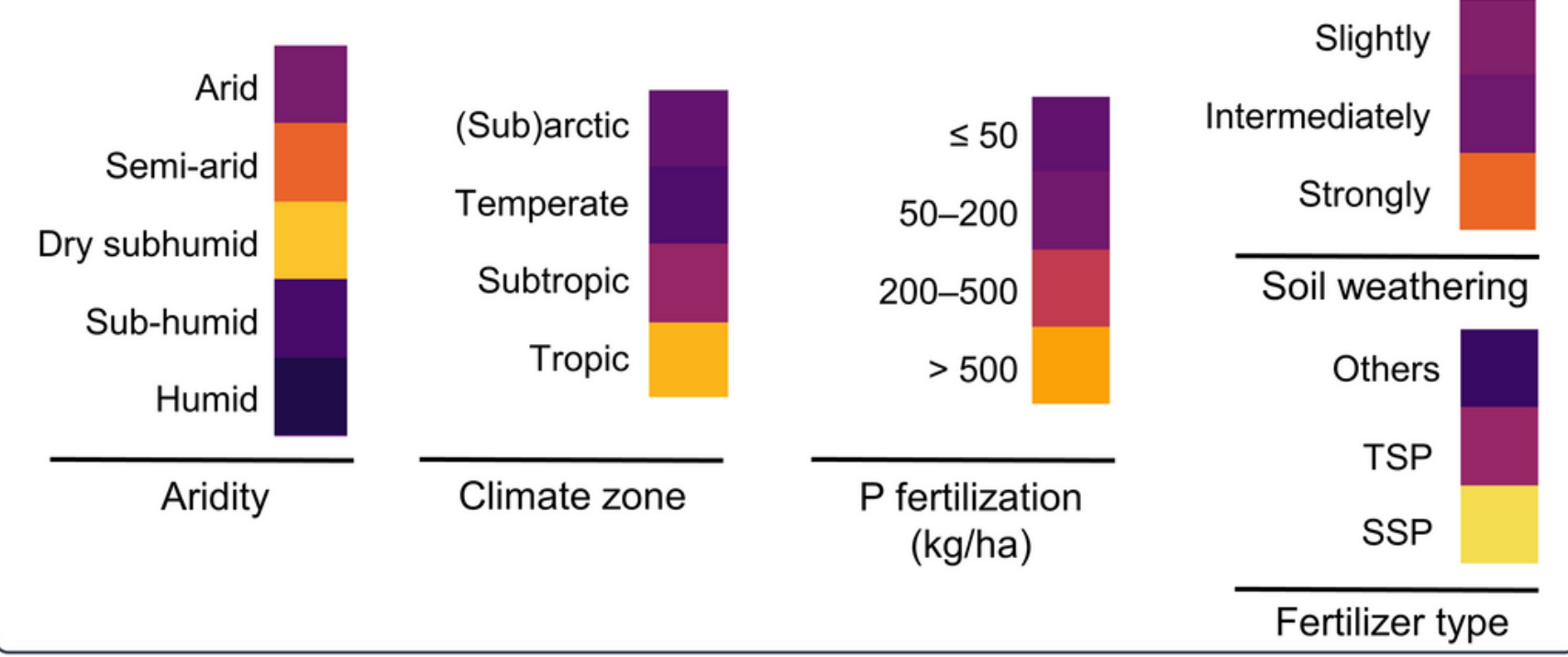




\section{Figure 2}

Current Phosphorus $(P)$ fertilization practices are largely inefficient and determined by several factors besides the $\mathrm{P}$ fertilizer amount applied to soil. Heatmap illustrating (a) the size of the effect that the listed factors can have in limiting the variance of above-ground crop production; (b) the effect that $P$ fertilization can have in increasing aboveground plant production in function of the properties of the cropland (aridity, climate zone, soil weathering) and the $\mathrm{P}$ fertilization regime (amount and fertilizer type); and (c) P use efficiency in common crop cereals. $P$ fertilizer use efficiency for grain (left) is calculated as follows: ( $P$ content in grain with $P$ fertilization - $P$ content in grain without $P$ fertilization)/ $P$ fertilizer amount applied $\times 100 \%$. $P$ fertilizer use efficiency for above-ground mass production (right) was calculated as follows ( $\mathrm{P}$ content in aboveground biomass with $\mathrm{P}$ fertilizer $-\mathrm{P}$ content in aboveground biomass without $\mathrm{P}$ fertilizer)/P fertilizer amount $\times 100 \%$. (a) and (b) heatmaps are based on the data published by Hou et al. 2020. The heatmap presented in (c) is based on the data published by Yu et al. 2021. We strongly urge the reader to consult the original studies by Hou et al. 2020 and Yu et al. 2021 which present, to our knowledge, the most comprehensive data analyses on the global influence of $\mathrm{P}$ limitation and $\mathrm{P}$ fertilizer use efficiency in above-ground plant production in both natural and agricultural environments. Heat maps were prepared using ComplexHeatmaps R package (Gu et al., 2016). 

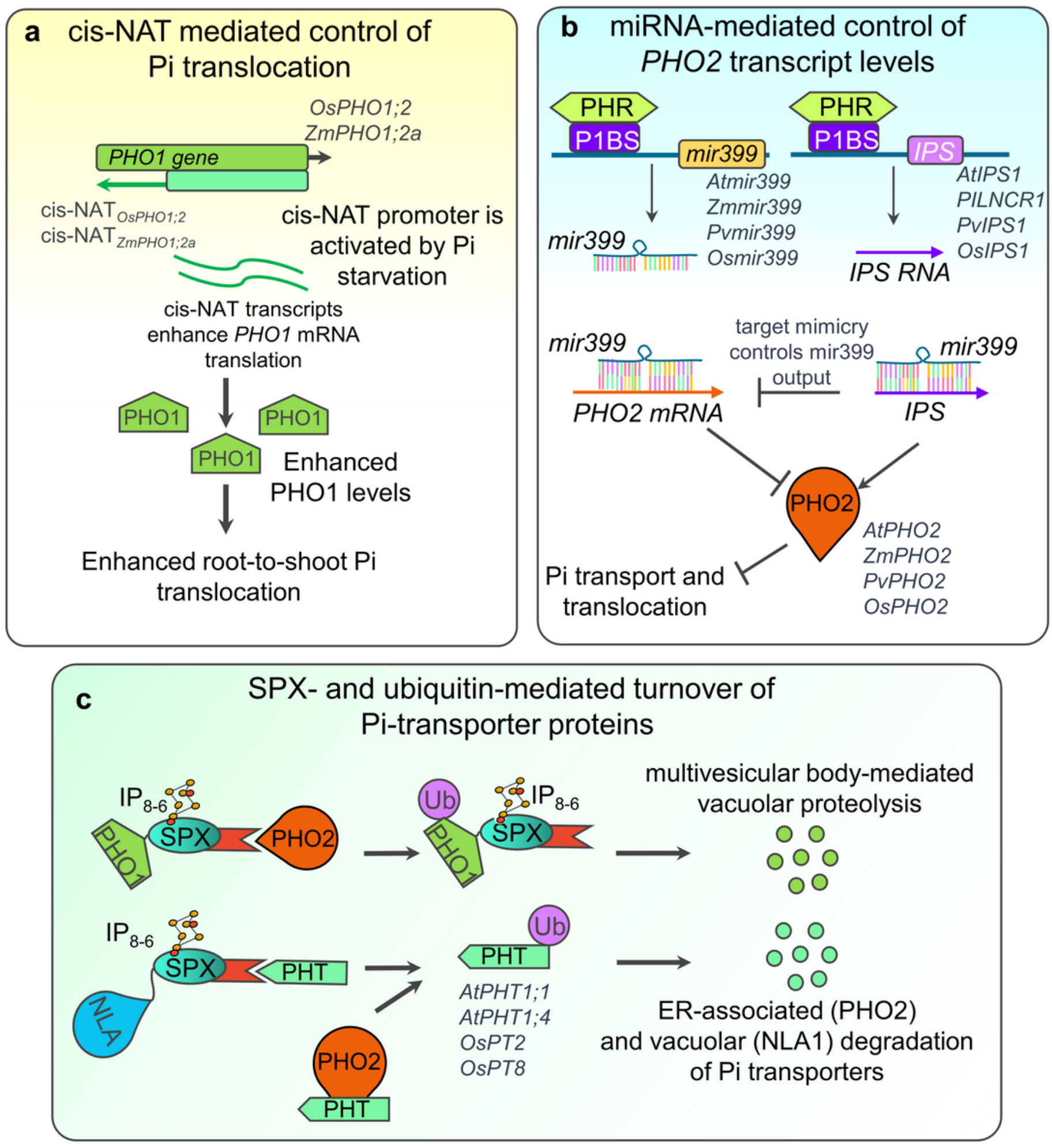

Figure 3

Regulons controlling plant phosphate (Pi) homeostasis. Schematic summary of (a) cis-NAT mediated control of Pi translocation; (b) miRNA-mediated control of PHO2 transcript levels; and (c) ubiquitinmediated turnover of Pi-transporter proteins in plants. Explanation and discovery of the regulons for Arabidopsis and crops is presented throughout the text. 
a

IP binding triggers SPX conformational changes

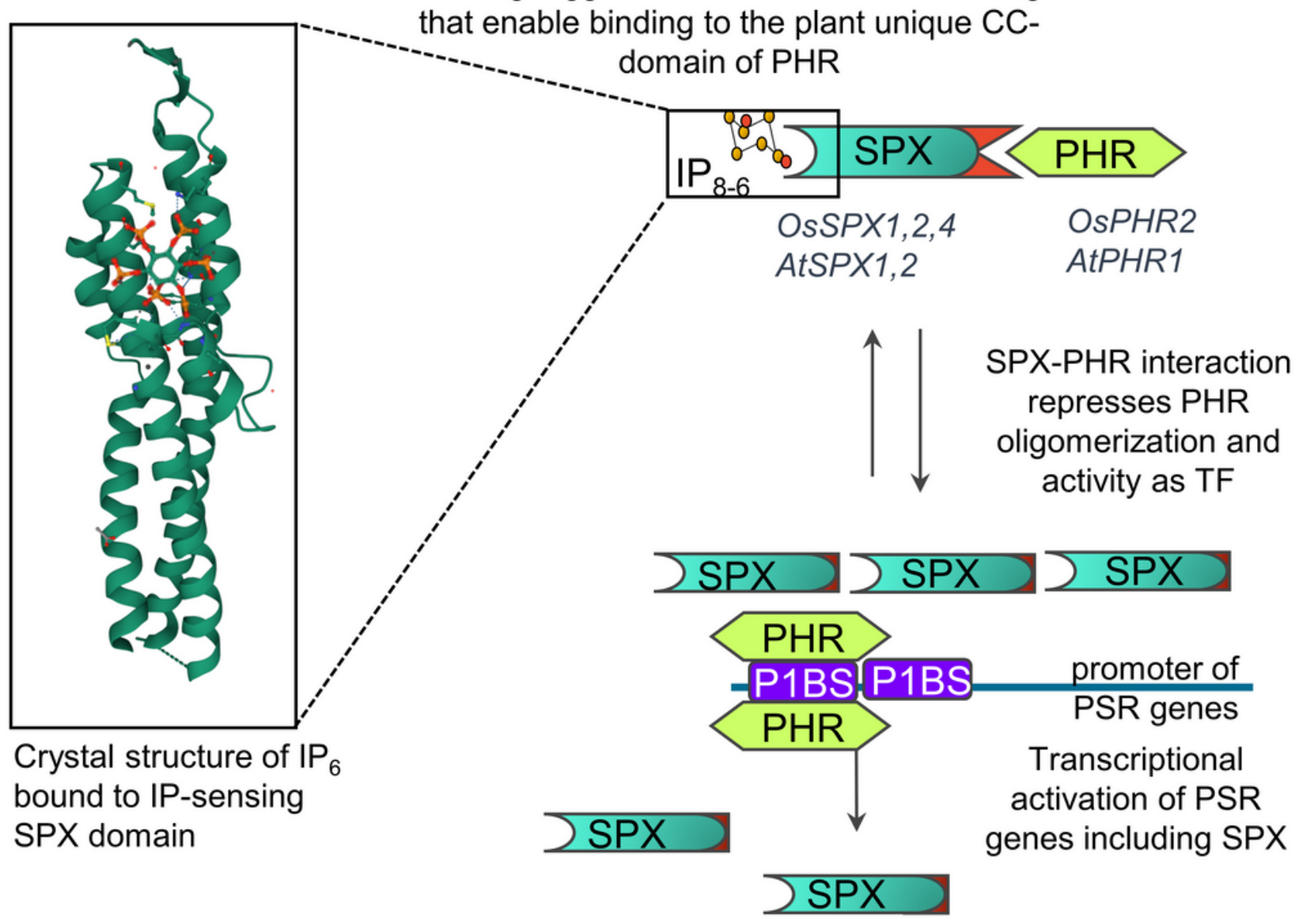

b

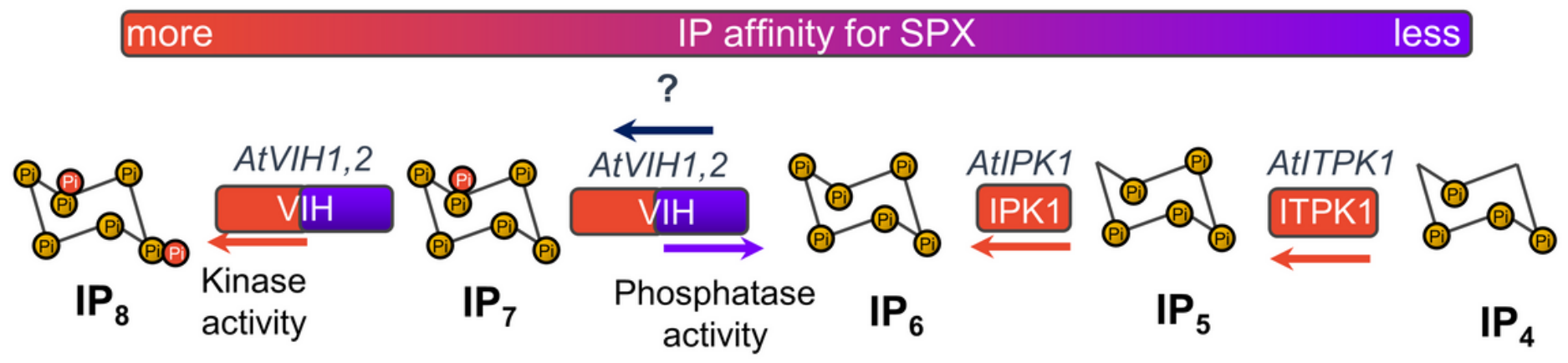

\section{IP synthesis in Arabidopsis}

Figure 4

Control of plant phosphate (Pi) homeostasis by inositol (IP)-signaling and IP-sensing domains. (a) Schematic representation of SPX-domain regulation on plant PHR transcription factors. See main text for complete explanation. Because SPX-domains are IP-sensing domains conserved among eukaryotes (Wild et al. 2016), the crystal structure of IP6-bound SPX domain from the fungi Chaetomium thermophilum is presented as an example. (b) Representation of IP synthesis in plants. Dual phosphatase/pyrophosphate kinases $\mathrm{AtVIH} 1$ and $\mathrm{AtVIH} 2$ phosphorylate InsP7 to produce InsP8 and dephosphorylate InsP7 to InsP6. It 
is currently unknown which enzyme catalyzes the formation of InsP7. AtIPK1 and AtITPK1 kinases catalyze respectively the subsequent phosphorylation of IP4 to IP5 and to further IP6.

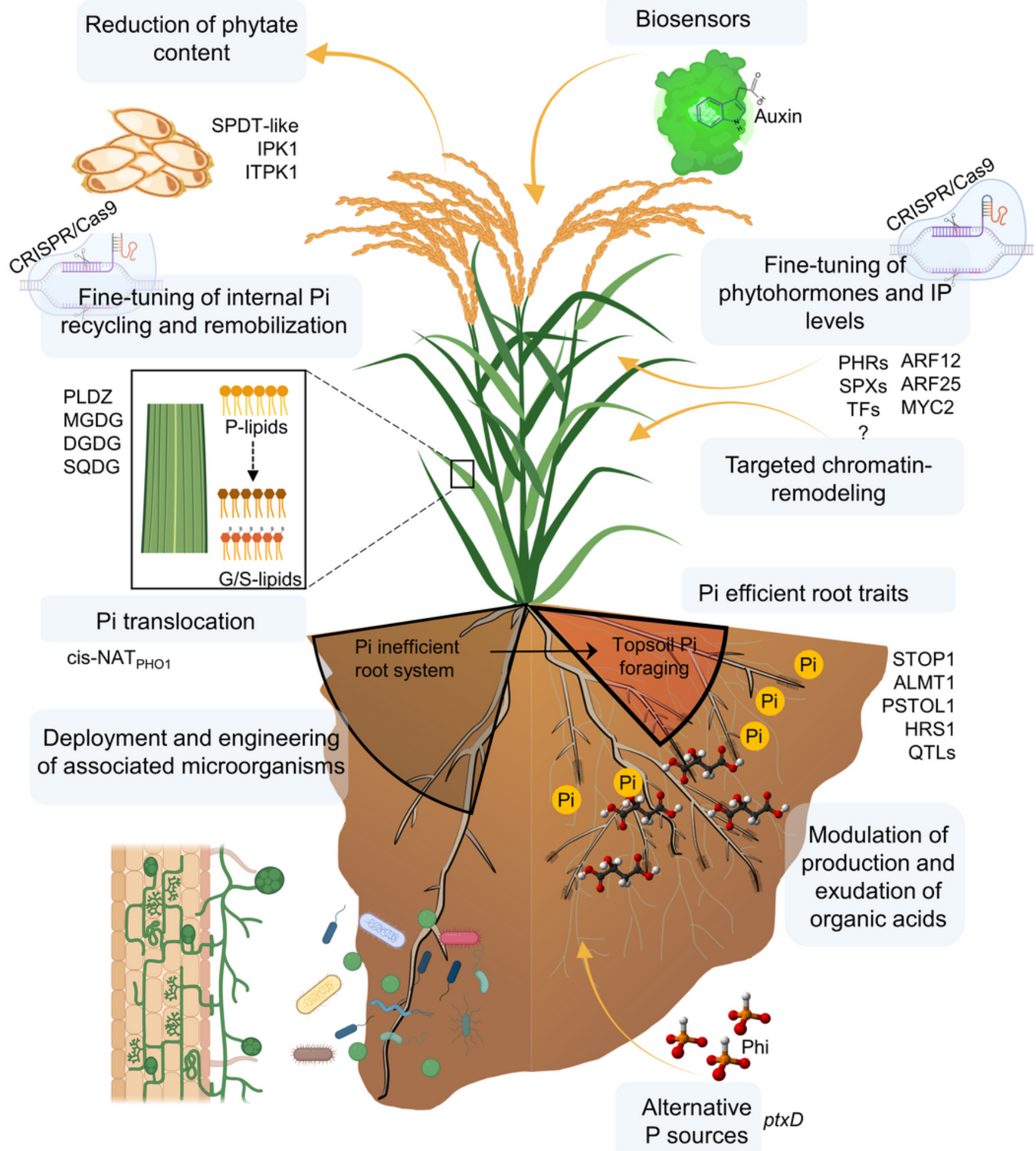

\section{Figure 5}

Overview of traits and strategies to develop low-phosphate (Pi) tolerance in crops. Several traits and strategies have potential to develop low Phosphorus $(\mathrm{P})$ tolerant crops. These include strategies related to the deployment and engineering of plant associated microorganisms, the use of alternative P sources 
like phosphite (Phi), and the improvement of the plant genetics based on current knowledge of the molecular regulation of Pi starvation responses. This latter considers the fine-tuning of different traits such us Pi recycling and remobilization, phytohormones and inositol polyphosphate molecules (IP) levels and modulation of organic acids exudation. The use of the CRISPR/Cas 9 technology together with more integrative synthetic biology approaches assisted by biosensor molecules could help speed up this process. Phospholipids (P-lipids), galactolipids (G-lipids), sulfolipid (S-lipids). Some elements in this figure were designed using BioRender. 